\title{
Enhanced Performance of Hydrogen Peroxide Modified Pozzolan-based Geopolymer for Abatement of Methylene blue from Aqueous Medium
}

\section{Dzoujo Tamaguelon Hermann}

University of Douala: Universite de Douala

Tome Sylvain ( $\square$ sylvatome@yahoo.fr)

University of Douala https://orcid.org/0000-0001-9200-7776

\section{Victor 0 Shikuku}

Kaimosi Friends University College

\section{Jean T Tchuigwa}

University of Douala: Universite de Douala

\section{Alex Spieß}

Universitat Wien Institut fur Anorganische Chemie und struktuchemie, universitat dusseldorf

\section{Christoph Janiak}

Universitat Wien Institut fur Anorganische Chemie und strukturchemie, Universitat dusseldorf

\section{Marie Annie Etoh}

University of Douala: Universite de Douala

\section{David Dina}

University of Douala: Universite de Douala

\section{Research Article}

Keywords: Pozzolan, eco-adsorbents, geopolymers, adsorption, methylene blue

Posted Date: May 19th, 2021

DOI: https://doi.org/10.21203/rs.3.rs-511676/v1

License: (c) (1) This work is licensed under a Creative Commons Attribution 4.0 International License. Read Full License

Version of Record: A version of this preprint was published at Silicon on August 10th, 2021. See the published version at https://doi.org/10.1007/s12633-021-01264-4. 

Enhanced performance of hydrogen peroxide modified pozzolan-based geopolymer for abatement of methylene blue from aqueous medium

Dzoujo T. Hermann ${ }^{1}$, Sylvain Tome ${ }^{1}$, Victor O. Shikuku ${ }^{2}$, Jean T. Tchuigwa ${ }^{1}$, Alex Spieß ${ }^{3}$, Christoph Janiak $^{3}$, Marie Annie Etoh ${ }^{1}$, David Dina ${ }^{1}$

${ }^{1}$ Department of Chemistry, Faculty of Sciences, University of Douala, P.O. Box 24157, Douala, Cameroon

${ }^{2}$ Department of Physical Sciences, Kaimosi Friends University College, P.O. Box 385-50309 Kaimosi-Kenya

${ }^{3}$ Institut für Anorganische Chemie und Strukturchemie, Universität Düsseldorf, Universitätsstr. 1D-40225 Düsseldorf, Germany, Tel. int+49-211-81-12286

*Corresponding authors: P. Box, +237 697082352, Email: dinadavidcr@yahoo.com ; P. Box 2396, +237 694825926, Email: sylvatome@yahoo.fr

\section{Abstract}

Pozzolan-based eco-adsorbents were synthesized by geopolymerization with addition of hydrogen peroxide $\left(\mathrm{H}_{2} \mathrm{O}_{2}\right)$ with mass ratios $0 \%\left(\mathrm{GP}_{0}\right)$ and $1 \%\left(\mathrm{GP}_{1}\right)$ and the products used to sorb cationic methylene blue (MB) dye from water. The chemical composition, textural properties, mineral composition, surface functions, as well as morphology and internal structure of these samples were determined by the X-ray fluorescence, adsorption of nitrogen by the B.E.T (Bruamer Emmet Teller) method, X-ray diffraction, Fourier Transformed Infrared Spectroscopy (FTIR) and scanning electron microscopy (SEM), respectively. The effects of contact time, dye initial concentration, adsorbent dosage, $\mathrm{pH}$ and temperature were examined and are herein reported. Incorporation of $1 \% \mathrm{H}_{2} \mathrm{O}_{2}$ increased the specific surface area from 4.344 to $5.610 \mathrm{~m}^{2} / \mathrm{g}$ representing $\sim 29 \%$ increase in surface area. This translated an increase in the MB adsorption capacity by 15 orders of magnitude from 24.4 to $366.2 \mathrm{mg} / \mathrm{g}$ for $\mathrm{GP}_{0}$ and $\mathrm{GP}_{1}$, respectively. The adsorption rates of methylene blue on the two geopolymers were best described by the pseudo-second order kinetic model. The adsorption equilibrium data were best described by the Sips and Freundlich isotherms models for $\mathrm{GP}_{0}$ and $\mathrm{GP}_{1}$, respectively. Thermodynamically, it was determined that the adsorption of methylene blue onto $\mathrm{GP}_{0}$ and $\mathrm{GP}_{1}$ is a physical and endothermic process. The results show that incorporation of low amount of 
hydrogen peroxide into pozzolan-based geopolymers increases their adsorption capacity for methylene blue dye stupendously while preserving the surface chemistry.

Keywords: Pozzolan, eco-adsorbents, geopolymers, adsorption, methylene blue

\section{Introduction}

The problem of environmental pollution is still a topical issue because many industrial activities continue to generate various traditional and emerging pollutants, likely to create significant nuisance such as the destruction of aquatic fauna and flora [1]. Indeed, industrial effluents are among the major sources of environmental pollution. Additionally, these pollutants have the capacity to bioaccumulate along the food chain and accumulate in certain organs of the human body [2]. It is therefore essential to eliminate these toxic elements present in the industrial effluents or to reduce their concentrations below the admissible thresholds defined by the stipulated standards [1]. Faced by increasingly restrictive regulations, industries must obligatorily treat their effluents before discharging into the environment. To fight against this environmental issue, research in identification and elimination of water pollutants, such as methylene blue, directly involved in the appearance of imbalances in ecosystems like photosynthesis inhibition, under oxygenation, bioaccumulation or inducing serious disorders that can harm health such respiratory problems or even lead to death, both in animals and humans, is ever increasing [3].

For this purpose, various classical pollutant removal techniques are used namely coagulation, flocculation, filtration, advanced oxidation processes (AOPs) and adsorption onto activated carbons. Though traditional approaches are insufficient in removing dyes from water to molecular levels, advanced oxidation processes are very expensive and toxic by-products are formed in the process of dye removal [4]. On the other hand, activated carbon is very expensive and the cost of regeneration is also very high [5]. The development of eco-friendly and costeffective technologies are more and more desired to preserve the environment and for sustainability, respectively. Among the different treatment processes of dye-containing water effluents, adsorption stands out to be one the techniques relatively easy to use, easy to set up and of diverse variety of adsorbents that can used such as: biomass-derived activated carbons, clays and pozzolans among others [6]. The latter is an abundant and inexpensive natural resource in the world. Cameroon is counted among the largest producers of natural pozzolan, producing approximately $600 \mathrm{Kt} / \mathrm{year}$ [7]. It consists mainly of oxides of silicon, aluminum 
and iron $\left(\mathrm{SiO}_{2}, \mathrm{Al}_{2} \mathrm{O}_{3}\right.$ and $\left.\mathrm{Fe}_{2} \mathrm{O}_{3}\right)$ [8]. Pozzolan is used as a raw material in cement plants and in water treatment $[9,10]$. However, its use in the field of adsorption is still limited due to its low adsorbing power, relative to other adsorbents [10]. For judicious use of this natural resource, its adsorption characteristics must be improved. Several works on the synthesis and adsorption of industrial contaminants onto geopolymers based on clays and fly ashes have been reported in literature [11-13]. These studies demonstrate the efficiency of geopolymers in the elimination of dyes from water effluent. However, the rarity of industrial waste precursors in many developing countries especially in remote areas, relative to pozzolan, limit their exploration. The transformation of the pozzolan into amorphous zeolite (geopolymer) is a sustainable and inexpensive way for its utilization as adsorbent for water treatment. Geopolymerization only does not guarantee a high adsorbing product [14]. Consequently, several additives have been evaluated for amelioration the adsorption characteristics of geopolymers. Singhal et al. [15] reported the use of Cetyl trimethylammonium bromide (CTAB) to improve the textural characteristics of metakaolin-based geopolymer. Other approaches include the chemical modification using bivalent metallic ions such as nickel, zinc and barium $[16,17]$. These methods have their inherent limitation. CTAB is not only expensive but also changes the surface chemistry of the geopolymer. Alteration of the constitution of the geopolymer introduces site specific interactions that may induce specificity in the uptake of pollutants. Additionally, incorporation of bivalent heavy metals may cause secondary water pollution in case of leaching from the geopolymer framework. Simple, low-cost and environmentally benign methods are required for ameliorating the textural and adsorption characteristics of geopolymers. Hydrogen peroxide is known to decompose quickly in alkaline solution, the preparation conditions for geopolymer synthesis. The oxygen so-generated could be trapped in the geopolymer structure thus improving its porosity parameters and hence its adsorption performance while preserving its surface chemistry. The objective of this work was to ameliorate the adsorption characteristics of pozzolan-based geopolymers by preparation of a hydrogen peroxide modified pozzolan-based geopolymer as an eco-adsorbent. The effects of incorporation of hydrogen peroxide on the textural, structural and adsorptive performance for the removal of methylene blue dye from aqueous solution under various experimental conditions were examined and are herein reported.

\section{Materials and Methods}

\subsection{Geopolymer synthesis}


The pozzolan used as a source of aluminosilicate was obtained from the locality of Mbouroukou in the Littoral region of Cameroon, crushed and sieved through $100 \mu \mathrm{m}$ sieve to obtain uniform particle size. The alkaline activator solution was prepared by blending the sodium hydroxide (12M from $98 \%$ purity sodium hydroxide flake) and commercial water glass (28.7 wt. $\% \mathrm{SiO}_{2}$, 8.9 wt. $\% \mathrm{Na}_{2} \mathrm{O}$ and 62.4 wt. $\% \mathrm{H}_{2} \mathrm{O}$; density $1.37 \mathrm{~g} / \mathrm{mL}$ ). The ratio (liquid/liquid) of sodium hydroxide/commercial water glass was 2.4. The geopolymer was synthesized by mixing the alkaline solution and the pozzolan powder in a liquid/solid ratio of 0.3 . This blend was homogenized for 10 minutes using a mixer where a fresh paste was formed. To alter the porosity of the geopolymers, hydrogen peroxide in a mass ratio of $1 \%$ was added, as a blowing agent, to the paste previously left to rest for 30 minutes and it was then poured into cylindrical PVC moulds. Once moulded, the whole was mechanically compacted for one minute and then put in an oven (MEMMERT B2162385) at $60^{\circ} \mathrm{C}$ for 24 hours, then removed and left to rest for 4 days. The geopolymer samples obtained without (pristine) and with incorporation of hydrogen peroxide labeled $\mathrm{GP}_{0}$ and $\mathrm{GP}_{1}$, respectively, were then dipped in acetone for 2 hours to stop the geopolymerization process, then dried in the oven at $60^{\circ} \mathrm{C}$ for one hour. They were then crushed, sieved and washed until a neutral $\mathrm{pH}$ is obtained, then dried in an oven for 6 hours.

\subsection{Materials Characterization}

The pozzolan and the synthesized geopolymers were subjected to various physico-chemical characterizations in order to determine chemical composition, textural properties, mineralogical composition, surface functional groups, internal structure and morphology by the following methods:

\subsubsection{X-ray fluorescence}

The x-ray fluorescence spectrometry (XRF) method (Bruker-SRS 3400) was used to determine the bulk oxide composition of pozzolan.

\subsubsection{Iodine and methylene blue indices}

The iodine and methylene blue indices are determined following the method used by Mbaye [18] to evaluate the microporosity and macroporosity of eco-adsorbents. The procedures are as follows:

\subsubsection{Iodine Index}

In a $100 \mathrm{~mL}$ Erlenmeyer flask, $0.1 \mathrm{~g}$ of geopolymers previously dried in an oven at $110^{\circ} \mathrm{C}$ for 24 hours were brought into contact with $20 \mathrm{~mL}$ of $0.02 \mathrm{~N}$ iodine solution mixture stirred for 4 
to $5 \mathrm{~min}$ and then filtered. Subsequently, $10 \mathrm{~mL}$ of the filtrate was titrated with sodium thiosulfate solution $(0.1 \mathrm{~N})$ using starch as the color indicator.

\subsubsection{Methylene Blue Index}

In a $100 \mathrm{~mL}$ Erlenmeyer flask, $0.1 \mathrm{~g}$ of previously dried geopolymers and $50 \mathrm{~mL}$ of methylene blue solution were mixed, and the mixture stirred for 4 to 5 minutes and then filtered. The residual methylene blue concentration was determined using a UV - visible spectrophotometer (MERCK spectroquant Pharo $300 \mathrm{UV} /$ visible instruments) at a wavelength of $662 \mathrm{~nm}$.

\subsubsection{The point of zero charge (pHpzc)}

The point of zero charge was determined following the protocol described by Karadag (2007) [19]. Briefly, six $\mathrm{NaCl}$ control solutions $(0.1 \mathrm{M})$ with a $\mathrm{pH}$ between 2 and 12 are prepared. To $20 \mathrm{~mL}$ of each of these solutions is added $0.1 \mathrm{~g}$ of adsorbent. The suspensions obtained are left to stand for 8 hours under stirring at room temperature, and their $\mathrm{pH}$ values are accurately determined using a pH meter (VOLTCRAFT PH-100ATC) after filtration.

\subsubsection{Nitrogen Adsorption and Surface Area Measurement}

Total surface area and micropore surface area of powder geopolymers were determined using $\mathrm{N}_{2}$ adsorption at $77 \mathrm{~K}$ in a Quantachrome Autosorb AS6AG Station 3 instrument (Institute of Inorganic chemistry and structural of Dusseldorf, Germany). The values of the two properties were calculated from experimental isotherms using the Brunauer-Emmett-Teller (BET) analysis method.

\subsubsection{X-ray Diffraction}

The crystalline phases present on the samples were determined using X-ray diffraction (XRD). An X-ray Powder Diffractometer (Bruker D8 Discovery, US) with the Bragg-Bretano thetatheta configuration, using a $\mathrm{CuK} \alpha$ radiation at $27.5 \mathrm{kV}$ and $25 \mathrm{~mA}$ was used for characterization. Spectra was obtained in the $2 \theta$ range from $6^{\circ}$ to $80^{\circ}$ with a step of $0.02^{\circ}$ and 1 second per step scan rate.

\subsubsection{Scanning Electron Microscopy}

Microscope equipped with Energy Microstructure analysis was carried out in some selected specimens by HITACHI S-3400N Scanning Electron Dispersive X-ray Spectrometry analysis (EDS), operating at $15.0 \mathrm{kV}$.

\subsubsection{Fourier Transform Infra-Red spectroscopy (FTIR)}


Fourier Transform Infra-Red spectroscopy (FTIR) permits the identification of functional groups on the surface of these materials. FTIR analysis of the samples was carried out by a FTIR Spectrophotometer (Nicolet 5700 FTIR, Thermo Electron Corporation) between 4000 and $400 \mathrm{~cm}^{-1}$ wavenumbers.

\subsection{Adsorption experiments}

Methylene Blue (MB) $\left(\mathrm{C}_{16} \mathrm{H}_{18} \mathrm{ClN}_{3} \mathrm{~S}_{\mathrm{x}} \mathrm{H}_{2} \mathrm{O}\right)$ solutions were prepared at pre-defined concentrations for adsorption experiments.

The adsorption experiments were carried out in batches at different initial values of dye concentrations $(10,20,30,40$ and $50 \mathrm{mg} / \mathrm{L})$ and contact time using a precisely weighed quantity of adsorbents $(0.1 \mathrm{~g})$ into a $50 \mathrm{~mL}$ diluted solutions. After equilibration of 30 minutes for $\mathrm{GP}_{1}$ material and 50 minutes for the $\mathrm{GP}_{0}$ material, the absorbance of residual solutions was measured using a spectrophotometer (MERCK spectroquant Pharo 300 UV/visible instruments) at a wavelength of the MB $(662 \mathrm{~nm})$.

The adsorption capacity at a given time and the percent removal $(\% \mathrm{R})$ of methylene blue were calculated using the following equations:

$$
\begin{aligned}
& q_{t}=\frac{\left(C_{0}-C_{t}\right) V}{m} \\
& R(\%)=\frac{\left(C_{0}-C_{t}\right) \times 100}{C_{0}}
\end{aligned}
$$

Where:

$\mathrm{q}_{\mathrm{t}}$ : The quantity adsorbed at time $\mathrm{t}(\mathrm{mg} / \mathrm{g}) ; \mathrm{C}_{0}$ : The initial dye concentration $(\mathrm{mg} / \mathrm{L})$;

$\mathrm{C}_{\mathrm{t}}$ : The dye concentration at time $\mathrm{t}(\mathrm{mg} / \mathrm{L}) ; \mathrm{V}$ : The volume of the solution $(\mathrm{mL})$ and

$\mathrm{m}$ : The mass of the adsorbent in solution $(\mathrm{g})$.

\subsubsection{Effect of contact time}

The tests were carried out by mixing in a reactor, in turn, $0.1 \mathrm{~g}$ of each geopolymer with $50 \mathrm{~mL}$ of the MB solution with a concentration of $50 \mathrm{mg} / \mathrm{L}$. The homogenization of the mixtures is ensured by a magnetic stirrer at a stirring rate of $120 \mathrm{rpm}$ during time intervals of 10, 20, 30, 40, 50 and 60 minutes.

\subsubsection{Effect of the initial concentration}

Diluted methylene blue solutions of $50 \mathrm{~mL}$ at different concentrations (10, 20, 30, 40 and 50 $\mathrm{mg} / \mathrm{L}$ ) were prepared and introduced into 5 reactors. A mass of $0.1 \mathrm{~g}$ of different geopolymers was added to each of these reactors and the mixture was stirred until the fixed equilibrium times 
of 30 minutes for $\mathrm{GP}_{1}$ material and 50 minutes for the $\mathrm{GP}_{0}$ material, respectively, filtered and residual $\mathrm{MB}$ determined.

\subsubsection{Effect of $\mathrm{pH}$}

The effect of $\mathrm{pH}$ was examined by varying the $\mathrm{pH}$ of the $\mathrm{MB}$ solution from 2 to 12 using a solution of hydrochloric acid $\mathrm{HCl}(0.1 \mathrm{~N})$ or caustic soda $\mathrm{NaOH}(0.1 \mathrm{~N})$ depending on the desired $\mathrm{pH}$.

\subsubsection{Effect of adsorbent dosage}

To various MB solutions with a concentration of $50 \mathrm{mg} / \mathrm{L}$, masses of $0.05,0.1,0.2,0.3,0.4$ and $0.5 \mathrm{~g}$ of each geopolymers, singly, was added and stirred at time intervals of 30 minutes for $\mathrm{GP}_{1}$ material and 50 minutes for the $\mathrm{GP}_{0}$ material. Subsequently, the different samples were filtered and residual MB concentration determined.

\subsubsection{Effect of temperature}

A fixed mass $(0.1 \mathrm{~g})$ of different geopolymers was added to $50 \mathrm{mg} \mathrm{L}^{-1}$ of MB solutions $(50 \mathrm{~mL})$. The temperatures were adjusted between $309-339 \mathrm{~K}$ and the contents agitated until equilibration (30 minutes for $\mathrm{GP}_{1}$ material and 50 minutes for the $\mathrm{GP}_{0}$ material) and the residual dye concentration in solution determined.

\section{Results and Discussion}

\subsection{XRF analysis}

The chemical composition of pozzolan, as determined by XRF analysis, is presented in Table 1. The main oxides in pozzolan are $\mathrm{SiO}_{2}, \mathrm{Al}_{2} \mathrm{O}_{3}$ and $\mathrm{Fe}_{2} \mathrm{O}_{3}$ constituting $75.98 \%$. Considering the potential reactivity of these oxides, the pozzolan was considered suitable for the development of geopolymers [20].

Table 1. Chemical composition of pozzolan $(\mathrm{Pz})$.

\begin{tabular}{lllllllllll}
\hline Oxides & $\mathrm{SiO}_{2}$ & $\mathrm{Al}_{2} \mathrm{O}_{3}$ & $\mathrm{CaO}$ & $\mathrm{Fe}_{2} \mathrm{O}_{3}$ & $\mathrm{Na}_{2} \mathrm{O}$ & $\mathrm{K}_{2} \mathrm{O}$ & $\mathrm{MgO}$ & $\mathrm{Cl}$ & $\mathrm{SO}_{3}$ & $\mathrm{LOI}$ \\
\hline $\mathrm{Pz}(\%)$ & 47.74 & 15.36 & 8.25 & 12.88 & 3.62 & 1.11 & 6.45 & - & - & 0.66 \\
\hline
\end{tabular}

\subsection{Textural Properties}

\subsubsection{Diameter, pore volume and specific area}

Table 2 shows the results from the analysis of $\mathrm{N}_{2}$ adsorption-desorption isotherm curves (Figure 1) as well as the iodine and methylene blue indices. It can be seen that the addition of hydrogen peroxide, which decomposes into water molecules and oxygen during synthesis, appreciably increased the specific surface area, as well as the total pore volume within the material from 
4.344 to $5.610 \mathrm{~m}^{2} / \mathrm{g}$ and 6.022 to $9.747\left(\times 10^{-3} \mathrm{~cm}^{3} / \mathrm{g}\right)$ for $\mathrm{GP}_{0}$ and $\mathrm{GP}_{1}$, respectively. The low values of iodine $\left(444.150 \mathrm{~m} / \mathrm{g}\right.$ for $\mathrm{GP}_{0}$ material and $571.050 \mathrm{~m} / \mathrm{g}$ for $\mathrm{GP}_{1}$ material) and methylene blue $\left(20 \mathrm{~m} / \mathrm{g}\right.$ for $\mathrm{GP}_{0}$ material and $23.680 \mathrm{~m} / \mathrm{g}$ for $\mathrm{GP}_{1}$ material) indices indicate that these geopolymers are very mesoporous. This is confirmed by the pore diameters (respectively 105.800 and $103.700 \AA$ for $\mathrm{GP}_{0}$ geopolymer and $\mathrm{GP}_{1}$ ) which are between 2 and $50 \mathrm{~nm}$ ) [21]. In addition, these both samples have displayed a characteristic type IV nitrogen adsorptiondesorption isotherm in accordance with the IUPAC scheme of classification, as shown in Figure 1[22]. Hysteresis loop in the $\mathrm{P} / \mathrm{P}_{0}$ range of $0.4-0.9$ denotes the presence of mesopores (pores in the range of 2-50 nm). The slight variation in the $\mathrm{N}_{2}$ adsorption-desorption isotherms from standard type IV isotherm could be related to the existence of hetero-sized pores [23].

Table 2: Physical properties of the different geopolymers

\begin{tabular}{llcllll}
\hline Adsorbents & $\begin{array}{l}\text { Pores } \\
\text { volume } \\
\left(\times \mathbf{1 0}^{-3} \mathbf{c m}^{\mathbf{3}} / \mathbf{g}\right)\end{array}$ & $\begin{array}{l}\text { total } \\
\text { diameter }\end{array}$ & $\begin{array}{l}\text { Pores } \\
\text { surface }\end{array}$ & $\begin{array}{l}\text { specific } \\
\left(\mathbf{m}^{2} / \mathbf{g}\right)\end{array}$ & $\begin{array}{l}\text { Iodine } \\
\text { number } \\
(\mathbf{m} / \mathbf{g})\end{array}$ & $\begin{array}{l}\text { MB } \\
\text { number } \\
(\mathbf{m g} / \mathbf{g})\end{array}$ \\
\hline $\mathrm{GP}_{0}$ & 6.022 & 105.800 & 4.344 & 444.150 & 20.000 & 7.5 \\
& & & & & & \\
\hline $\mathrm{GP}_{1}$ & 9.747 & 103.700 & 5.610 & 571,050 & 23.680 & 7.5
\end{tabular}

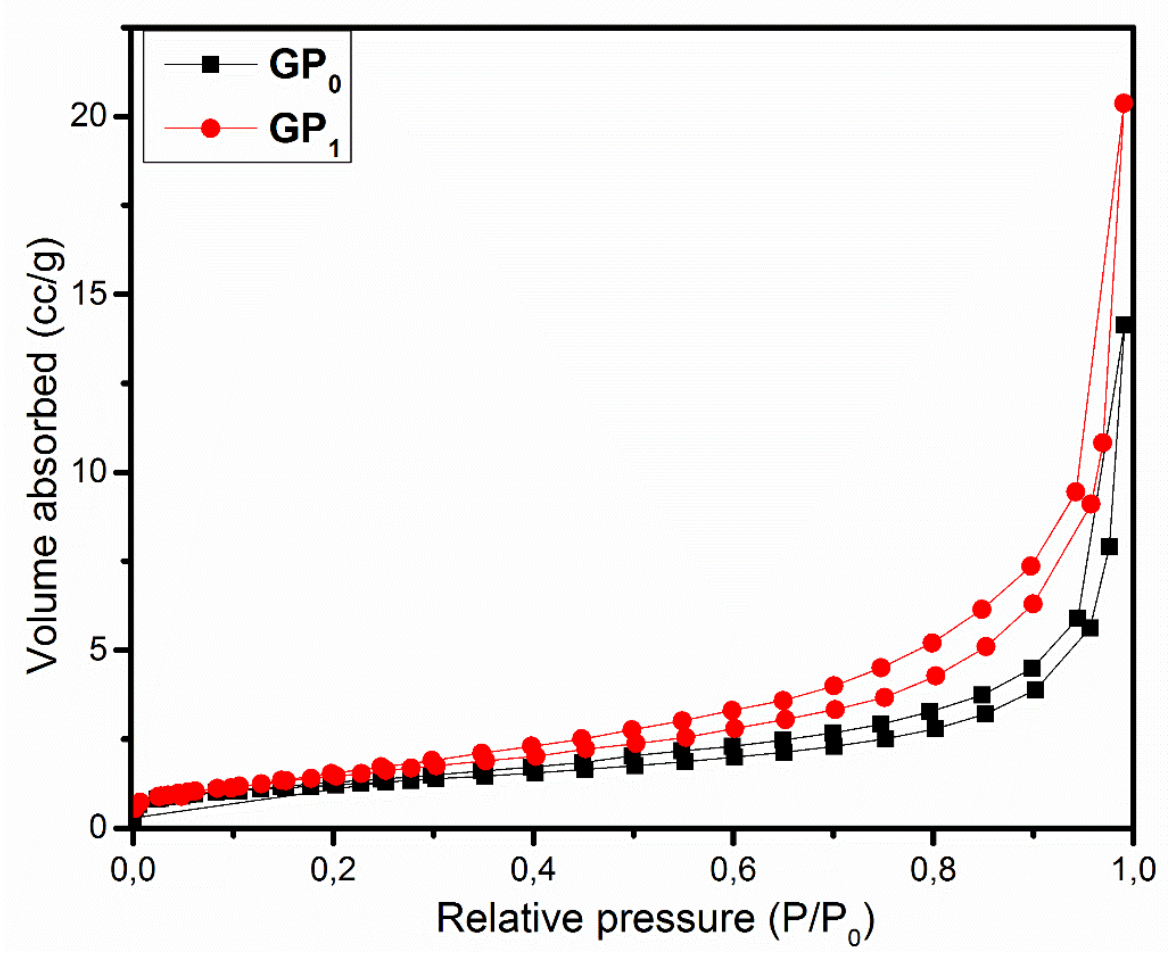


Figure 1: $\mathrm{N}_{2}$ adsorption-desorption isotherms of eco-adsorbents materials

\subsubsection{Point of zero charge $\mathrm{pH} H \mathrm{PzC}$}

As for the $\mathrm{pH}$ at the point of zero charge (Figure 2), it can be seen that the different geopolymers have the same pHPZC (7.5). These values are comparable to those reported by Sarkar [16] for an alkali-activated Linz Donawitz (LD) slag. However, it also suggests that the incorporation of hydrogen peroxide during synthesis did not affect the surface functional groups. At solution $\mathrm{pH}$ values below the $\mathrm{pH}_{\mathrm{PZC}}$, these materials carry a net positive surface charge and a net negative surface charge at $\mathrm{pH}$ values higher than the $\mathrm{pH}_{\mathrm{PZC}}[24]$.

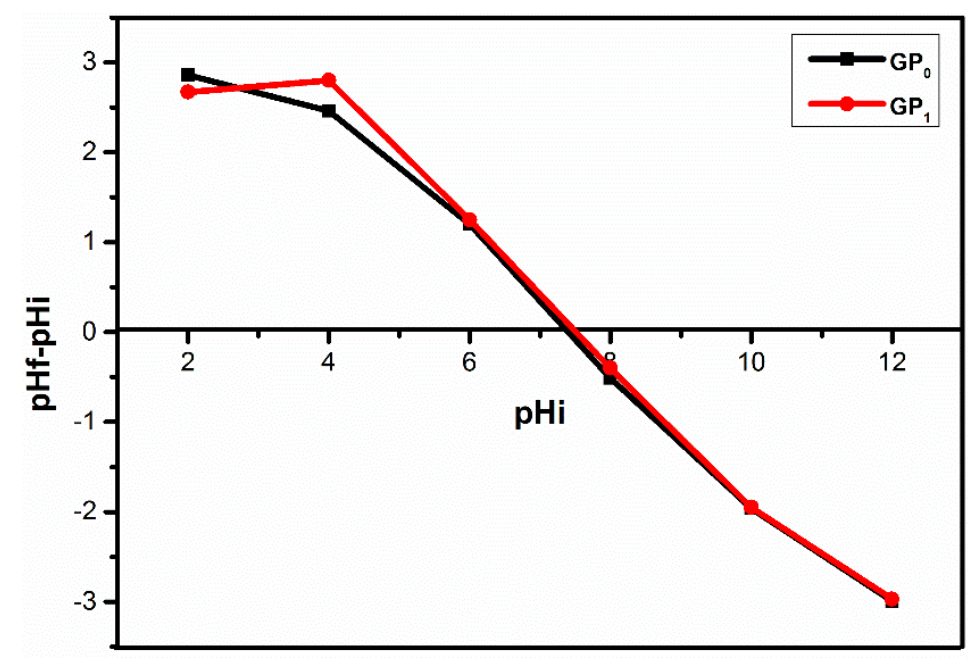

Figure 2: Point of Zero Charge of geopolymer materials.

\subsection{Functional groups analysis by FTIR}

The FTIR spectrum in figure 3 shows the vibration bands of the different materials recorded between 4000 and $400 \mathrm{~cm}^{-1}$. The pozzolan presents the following vibration bands: the first one between $3550-3400 \mathrm{~cm}^{-1}$ corresponds to the elongation vibrations of the $\mathrm{O}-\mathrm{H}$ bonds of water molecules [25]. The band around $1650 \mathrm{~cm}^{-1}$ is attributed to the deformation vibrations of the $\mathrm{H}-\mathrm{O}-\mathrm{H}$ bond of water molecules [26]. The bands centered between 1045-977 $\mathrm{cm}^{-1}$ corresponds to the symmetrical and asymmetrical elongations of the Si-O-Si and Si-O-Al bonds [27]. The bands between $913-736 \mathrm{~cm}^{-1}$ is related to the symmetrical vibrations of the Al-O and Al-OH. The bands around 550 and $460 \mathrm{~cm}^{-1}$ correspond to the symmetrical elongations of Si-O-Si, Al$\mathrm{O}-\mathrm{Al}, \mathrm{Si}-\mathrm{O}-\mathrm{Fe}$ and deformations of the $\mathrm{Si}-\mathrm{O}-\mathrm{Si}$, O-Si-O bonds, respectively. Comparing the spectrum of the precursor $(\mathrm{Pz})$ with those of the geopolymers $\left(\mathrm{GP}_{0}\right.$ and $\left.\mathrm{GP}_{1}\right)$, it is observed a shift of the main band of aluminosilicates from $\sim 1023$ to $\sim 1036 \mathrm{~cm}^{-1}$. This shift reflects a restructuring of the aluminosilicate phases present in the $\mathrm{Pz}$ material. It is also observed a 
decrease in intensity of the bands of aluminosilicates $\left(1023 \mathrm{~cm}^{-1}\right)$, silicates $\left(760 \mathrm{~cm}^{-1}\right)$ and ferrates $\left(436 \mathrm{~cm}^{-1}\right)$. This phenomenon confirms the dissolution of these phases in alkaline medium [28].

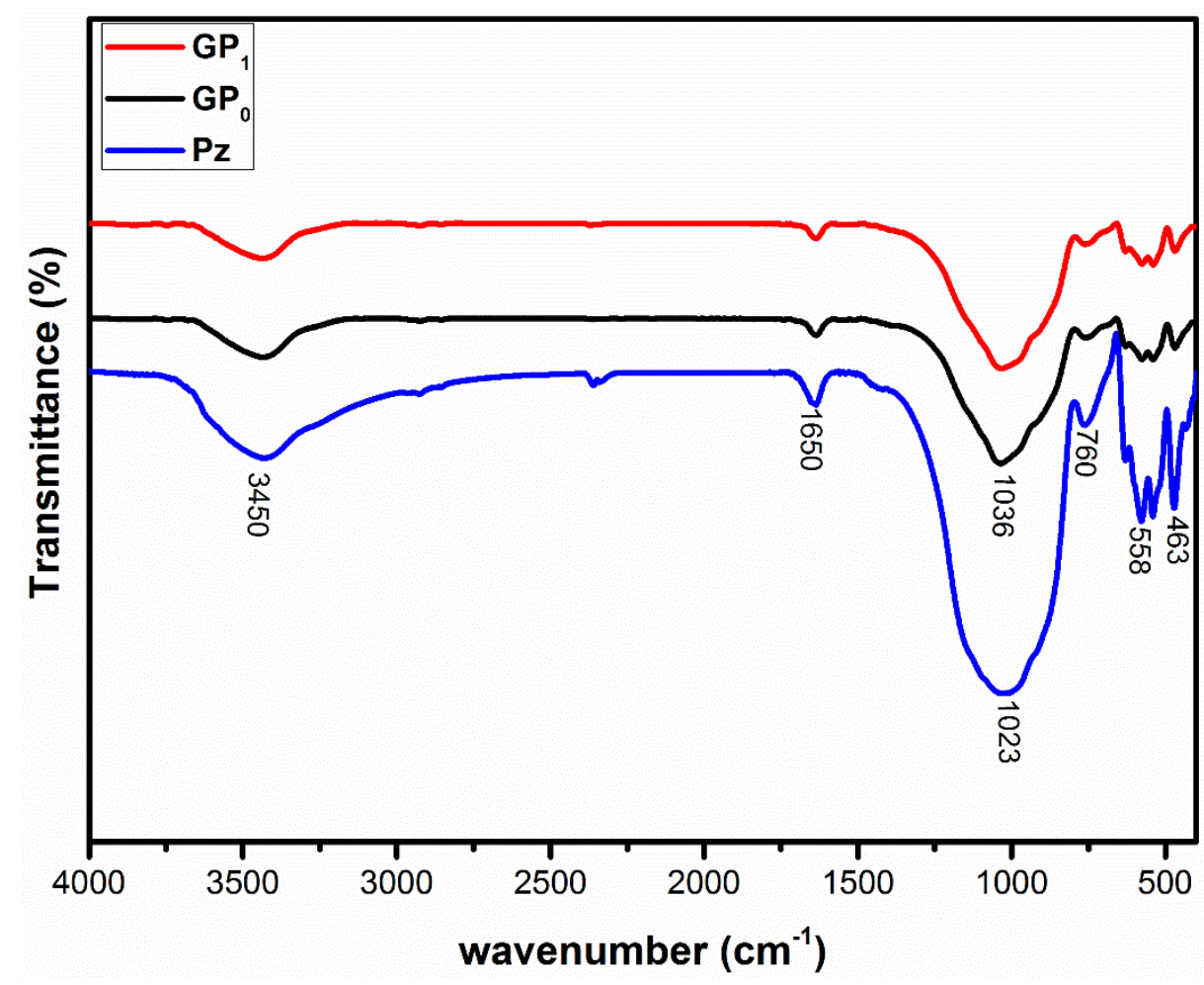

Figure 3: FTIR of the samples $\mathrm{Pz}, \mathrm{GP}_{0}$ and $\mathrm{GP}_{1}$

\subsection{X-ray diffraction analysis (XRD)}

The diffractograms of the two studied geopolymers $\mathrm{GP}_{0}$ and $\mathrm{GP}_{1}$ and aluminosilicate source $(\mathrm{Pz})$ used for their synthesis are shown in figure 4. The precursor is made in anorthite (An), $\mathrm{Na}\left(\mathrm{AlSi}_{3} \mathrm{O}_{8}\right)$ (PDF\#01-073-6461), feldspar-Na(F), (NaAlSi $\left.{ }_{3} \mathrm{O}_{8}\right)$ (PDF\#01-083-6911), forsterite (Fs), $\left(\mathrm{Mg}_{2} \mathrm{SiO}_{4}\right)$ (PDF \# 85-1462), diopside sodian (Ds), $\mathrm{Ca}(\mathrm{Mg}, \mathrm{Fe}, \mathrm{Al})(\mathrm{Si}, \mathrm{Al})_{2} \mathrm{O}_{6}(\mathrm{PDF} 338-$ 466), diopside alumina (Da), $\mathrm{Ca}(\mathrm{Mg}, \mathrm{Fe}, \mathrm{Al})(\mathrm{Si}, \mathrm{Al})_{2} \mathrm{O}_{6}$ (PDF\#38-0466), augite(A) $\left(\mathrm{Ca}_{0.61} \mathrm{Mg}_{0.76} \mathrm{Fe}_{0.49}\left(\mathrm{SiO}_{3}\right)_{2}\right.$, (PDF \#76-0544) and hematite(H), $\mathrm{Fe}_{2} \mathrm{O}_{3}$ (PDF\#03-0812) as mineral phases. Comparing the diffractograms of the aluminosilicate source $(\mathrm{Pz})$ to that of ecoadsorbent whitout blowing agent $\left(\mathrm{GP}_{0}\right)$, it is observed that all the original peaks are present conforming the low dissolution mentioned at the FTIR section. There is no noticeable shift of the amorphous hump located between $20^{\circ}$ and $35^{\circ}$ indicating the low transformation of the aluminosilicate phases to geopolymer networks. Observing also the diffractograms of the ecoadsorbents obtained without and whit addition of hydrogen peroxide $\left(\mathrm{GP}_{0}\right.$ and $\left.\mathrm{GP}_{1}\right)$, it is noticed 
the disappearances of the peaks at $32^{\circ}, 36^{\circ}$ and $63^{\circ}$. This fact reveals a probable dissolution of diopside alumina and diopside sodian minerals in hydrogen peroxide medium.

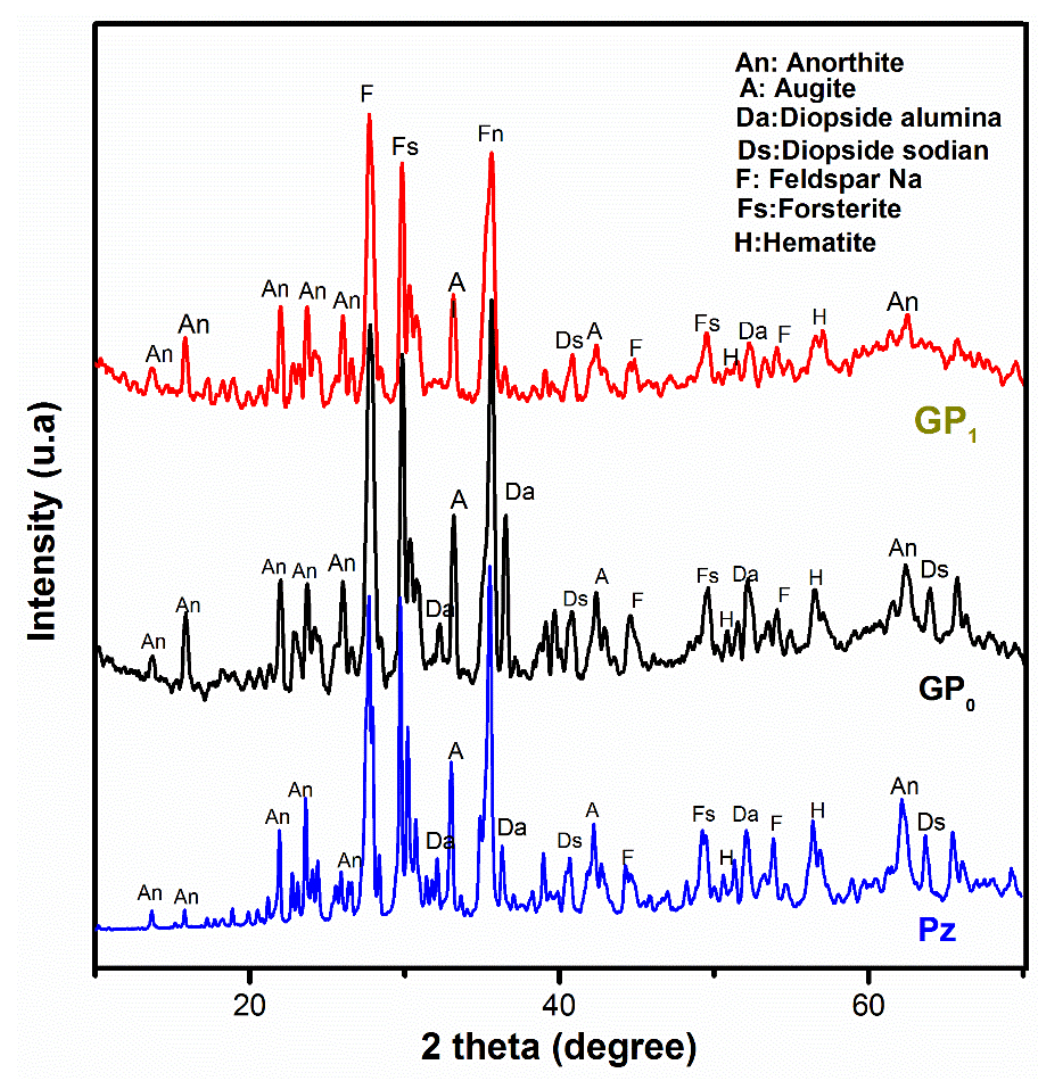

Figure 4: XRD patterns of precursor and $\mathrm{GP}_{0}$ and $\mathrm{GP}_{1}$ geopolymer

\subsection{Scanning electron microscopy and Energy Dispersive X-ray analysis (SEM/EDX)}

Figure 5 shows the micrographs of the $\mathrm{Pz}, \mathrm{GP}_{0}$ and $\mathrm{GP}_{1}$ materials associated with their elemental compositions (Table 3). The Figure 5a shows that the pozzolan is mainly made of crystalline phases and the EDX analysis reveals that these phases are aluminosilicate minerals, corresponding to those mentioned in the XRD section. Comparing the microstructural of $\mathrm{Pz}$ to that of $\mathrm{GP}_{0}$ material (Figure $5 \mathrm{~b}$ ), the observed densification of the microstructure of $\mathrm{GP}_{0}$ material due to polymerization/polycondensation of aluminosilicate phases to geopolymer networks. The micrograph (figure 5c) presents the capillary pores dispersed on the microstructure of geopolymer network. This fact discloses that the blowing agent affect the structure and the microstructure of geosorbent. The elemental composition of both materials confirms that silicate, aluminate and ferrate phases participate to the geopolymerization and the negative charges of geopolymer networks are balanced by $\mathrm{Na}^{+}, \mathrm{K}^{+}, \mathrm{Ca}^{2+}$ and $\mathrm{Mg}^{2+}$ ions. Moreover, considering the values of $\mathrm{Si} / \mathrm{Fe}$ ratios more significant than those of Si/Al (Table 3), it can be concluded that $\mathrm{GP}_{0}$ and $\mathrm{GP}_{1}$ geoadsorbents are made of poly (ferro- sialate-siloxo) 
chains. It should also be noted that the presence of cracks and capillary pores on the surface of the geopolymers $\mathrm{GP}_{0}$ (Figure 5b) and $\mathrm{GP}_{1}$ (Figure 5c) will constitute the access routes of the adsorbates to active sites of the framework during the adsorption process.

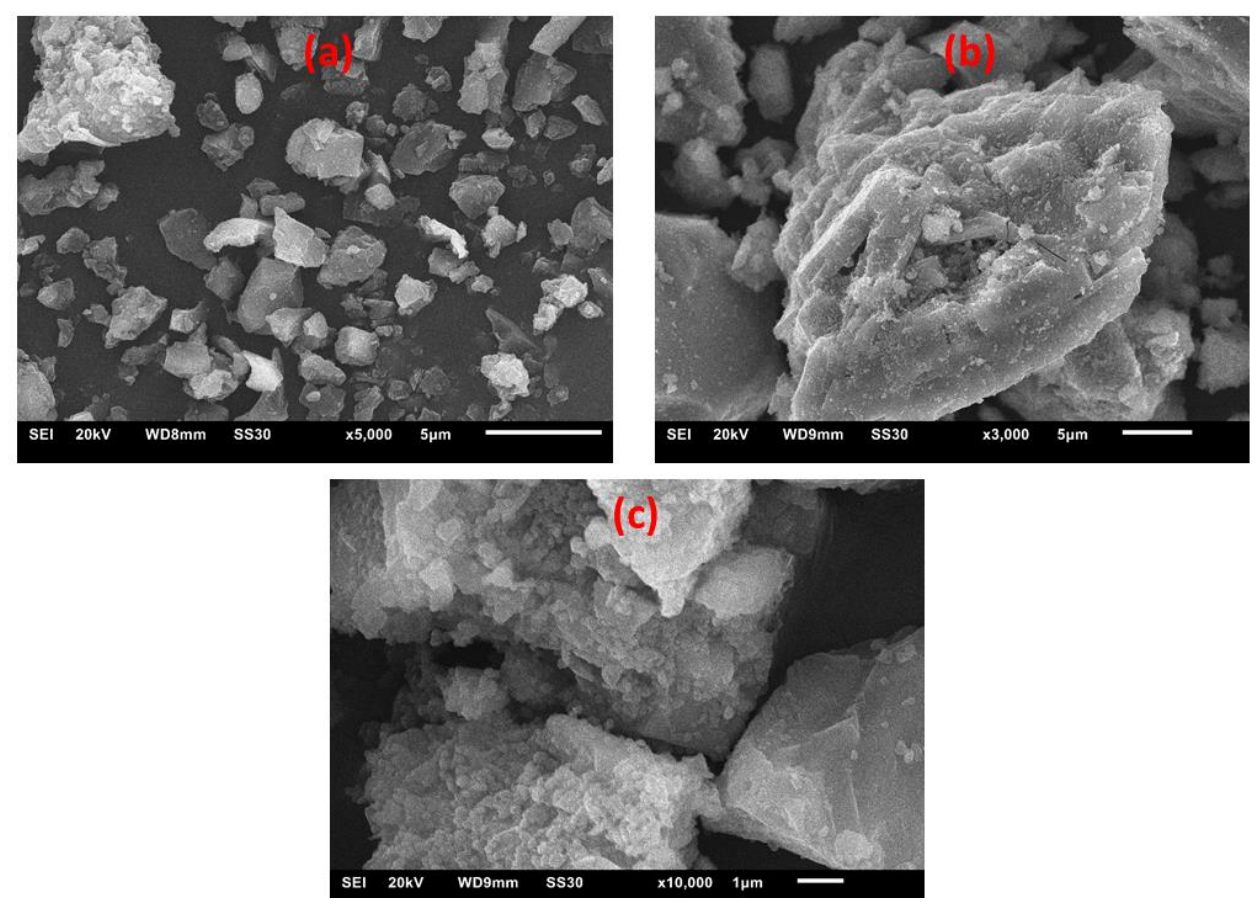

Figure 5: Scanning electron Microscopy of $\mathrm{Pz}(\mathrm{a}), \mathrm{GP}_{0}(\mathrm{~b})$ and $\mathrm{GP}_{1}$ (c)

Table 3: EDX analysis of the $\mathrm{Pz}, \mathrm{GP}_{0}$ and $\mathrm{GP}_{1}$ materials

\begin{tabular}{lllllllllll}
\hline Element & $\mathbf{S i}$ & $\mathbf{A l}$ & $\mathbf{F e}$ & $\mathbf{C a}$ & $\mathbf{M g}$ & $\mathbf{N a}$ & $\mathbf{K}$ & $\mathbf{O}$ & $\mathrm{Si} / \mathrm{Al}$ & $\mathbf{S i} / \mathbf{F e}$ \\
\hline Material & $\mathbf{P z}(\mathbf{a})$ & & & & & & & & & \\
\hline \%Element & 15.11 & 5.80 & 3.12 & 2.39 & 1.63 & 1.46 & 0.38 & 43.71 & 2.60 & 4.84 \\
\hline Material & $\mathbf{G P}(\mathbf{b})$ & & & & & & & & \\
\hline \%Element & 15.91 & 6.98 & 5.58 & 6.47 & 2.93 & 2.82 & 0.52 & 45.17 & 2.27 & 2.85 \\
\hline Material & $\mathbf{G P}(\mathbf{c})$ & & & & & & & & \\
\hline \%Element & 8.77 & 4.26 & 2.77 & 2.68 & 1.86 & 1.66 & 0.25 & 26.18 & 2.06 & 3.16 \\
\hline
\end{tabular}

\subsection{Influence of $\mathrm{pH}$}

Figure 6 represents the influence of $\mathrm{pH}$ on the adsorption capacities of MB generally revealed that the fixation of MB is unfavorable in acidic medium on the two eco-adsorbents due the electrostatic repulsion between the MB molecules and positively charged surfaces of these materials. In addition to this repulsion at $\mathrm{pH}$ below 5, an increased competition between $\mathrm{MB}$ 
cations and hydrogen ions $\left(\mathrm{H}^{+}\right)$for the active sites of the $\mathrm{GP}_{0}$ compared to $\mathrm{GP}_{1}$ is implied. In contrast, in a basic medium (at $\mathrm{pH}$ above 7.5 ), the $\mathrm{GP}_{0}$ and $\mathrm{GP}_{1}$ surfaces became more negative and the uptake of $\mathrm{MB}$ cations increased due to electrostatic attractions. The increase in negatively charged adsorption sites is attributed to deprotonation of the silanols $(\mathrm{SiO}-\mathrm{H})$ or aluminol (AlO-H) groups. This is consistent with the reports by Marouane and co-workers reported for MB sequestration by a metakaolin-based geopolymer [13].

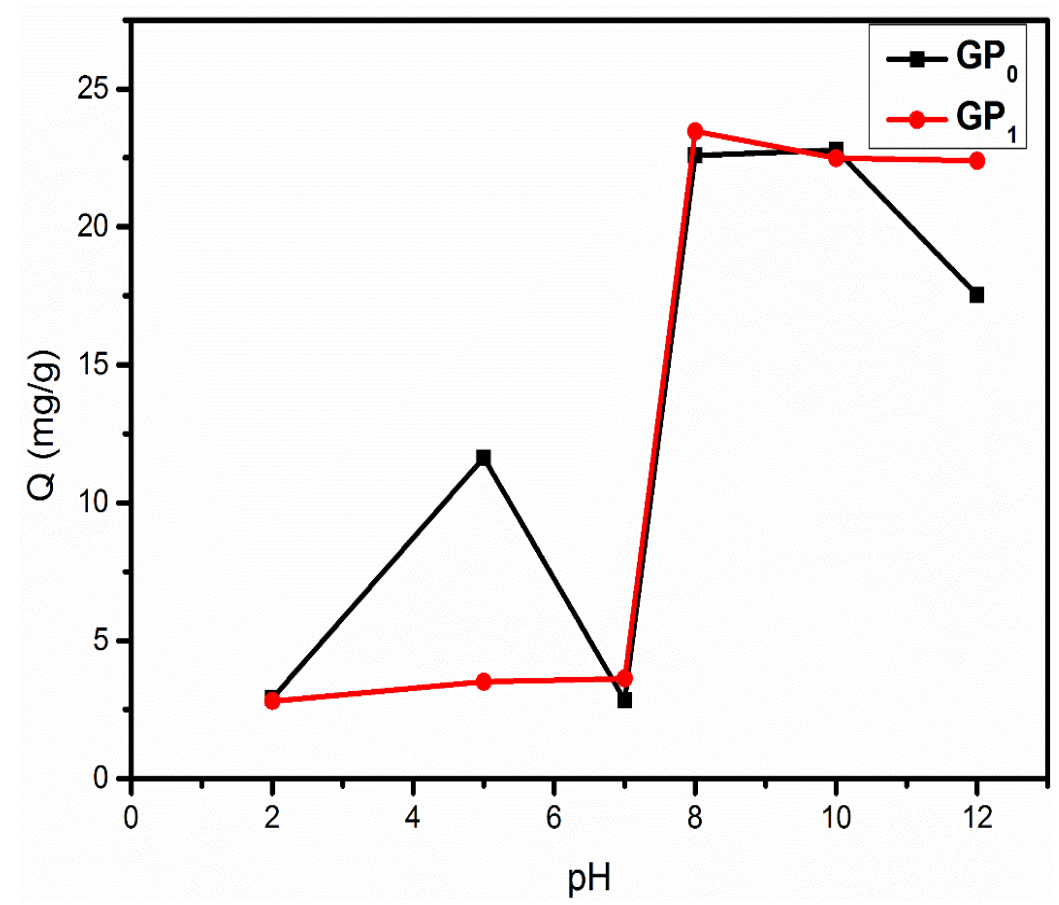

Figure 6: Influence of $\mathrm{pH}$ on the adsorption capacity of the different geopolymers.

\subsection{Effect of adsorbent dose}

Figure 7 shows that a mass of $0.2 \mathrm{~g}$ of geopolymers $\left(\mathrm{GP}_{0}\right.$ and $\left.\mathrm{GP}_{1}\right)$ is capable to sequester at most $97.79 \%$ and $99.39 \%$ of the initial MB in solution, respectively. Beyond this mass, the quantities of $\mathrm{MB}$ adsorbed decrease and with no appreciable change, indicating an agglomeration of certain adsorption sites due to excess mass [29]. It will, therefore, be useful to work with adsorbent doses less than or equal to $0.2 \mathrm{~g}$ to avoid inefficient overdosing. 


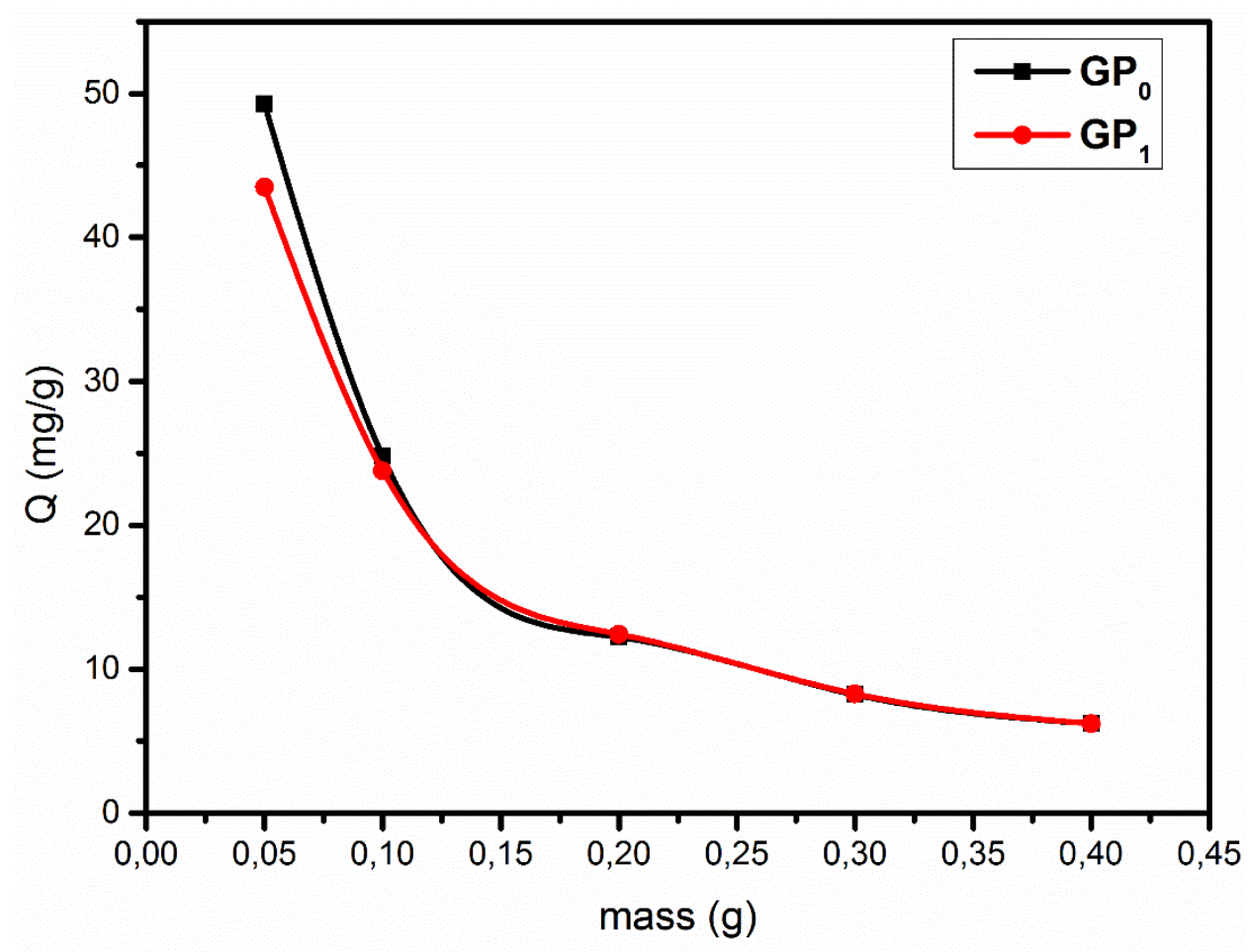

Figure 7: Influence of Adsorbent Dose

\subsection{Contact time}

Figure 8 represents the influence of contact time on the MB uptake by the $\mathrm{GP}_{0}$ and $\mathrm{GP}_{1}$. At the very beginning of the adsorption process, a rapid increase of the adsorbed quantities is observed. This process stabilizes after 10 minutes with the appearance of an equilibrium stage for both materials. Beyond $10 \mathrm{~min}$ a desorption phenomenon is observed which extends from the $10^{\text {th }}$ to the $20^{\text {th }}$ minute for the geopolymer $\mathrm{GP}_{1}$ and from the $10^{\text {th }}$ to the $30^{\text {th }}$ minute for the geopolymer $\mathrm{GP}_{0}$ where this phenomenon is very pronounced. The adsorption process is considered to have reached the pseudo-equilibrium state after 50 minutes for the $\mathrm{GP}_{0}$ material and 30 minutes for the $\mathrm{GP}_{1}$ material with adsorbed quantities of $\mathrm{MB}$ of $22.860 \mathrm{mg} / \mathrm{g}$ and $24.470 \mathrm{mg} / \mathrm{g}$, respectively. This kinetics can be explained by the fact that at the beginning of the process, there is a rapid occupation of the vacant adsorption sites by the MB molecules. As for the desorption phenomenon, it is due to the size of MB molecules (14.47 $\AA$ ) [30] which is much smaller than the pore diameters of the $\mathrm{GP}_{0}$ and $\mathrm{GP}_{1}$ and allows detachment of weakly adsorbed molecules. 


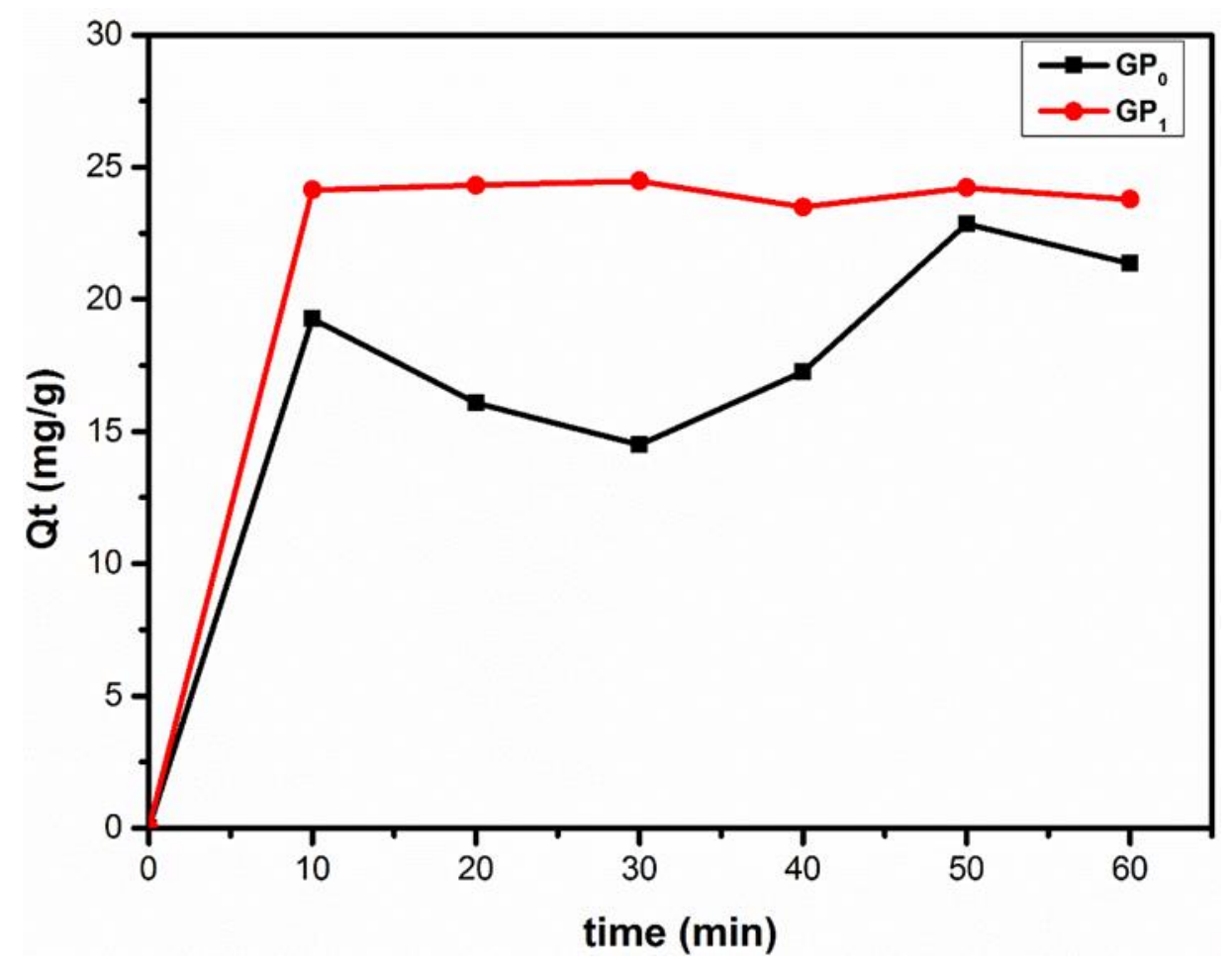

Figure 8: Effect of the MB contact time on the adsorption capacities of the different geopolymers

\subsection{Kinetic study}

In order to minimize errors due to linear regression as discussed in the works of Shikuku al. [31], and Chuncai al. [32], the non-linear regression method for the pseudo-first order, pseudosecond order and vermeulen kinetic models was applied to the experimental data to determine the best-fitting model, adsorption rate and predict the mechanism controlling the adsorption kinetics of methylene blue onto the geopolymers.

\subsubsection{Pseudo-first-order model or Lagergren model (PFO)}

The general Lagergren (1898) first-order rate expression is expressed as follows:

$$
\frac{d q_{t}}{d t}=k_{1}\left(q_{e}-q_{t}\right)
$$

Where $\mathrm{q}_{\mathrm{t}}(\mathrm{mg} / \mathrm{g})$ is the adsorbed amount at time $\mathrm{t}(\mathrm{min}), \mathrm{k}_{1}\left(\mathrm{~min}^{-1}\right)$ is the pseudo-first-order rate constant and $\mathrm{q}_{\mathrm{e}}$ is the equilibrium value of q. Integration of Eq. (4) with the initial condition $\mathrm{q}$ $=0$ at $\mathrm{t}=0$ gives

$q=q_{e}\left(1-e^{-k_{1} t}\right)$

The initial value for $\mathrm{k}_{1}$ may be obtained by using the half adsorption time $\mathrm{t}_{1 / 2}$ (defined as the time when $\mathrm{q}_{\mathrm{t}}=\mathrm{q}_{\mathrm{e}} / 2$ ) estimated from the kinetic data and the following relationship for the PFO 
Model.

$$
\begin{gathered}
K_{1}=\frac{\ln 2}{t_{1 / 2}} \\
S_{\text {rate }}=K_{1} q_{e}
\end{gathered}
$$

Where $S_{\text {rate }}\left(\mathrm{mg} \cdot \mathrm{g}^{-1} \cdot \mathrm{min}^{-1}\right)$ is the initial adsorption rate.

\subsection{2 pseudo-second-order (PSO)}

McKay and Ho (1998) presented a model to characterize the kinetics of adsorption taking into account both cases of a rapid fixation of solutes at the most reactive sites and that of a slow fixation at the weak sites energies. The rate law is written as follows:

$$
\frac{d q_{t}}{d t}=K_{2}\left(q_{e}-q_{t}\right)^{2}
$$

The integrated form can be written as

$q=\frac{K_{2} q_{e}^{2} t}{1+K_{2} q_{e} t}$

An initial trial value for $\mathrm{k}_{2} \mathrm{q}_{\mathrm{e}}$ may be obtained by using the following relationship for the PSO model

$$
K_{2} q_{e}=\frac{1}{t_{1 / 2}} \quad \text { With } \quad S_{\text {rate }}=k_{2} q_{e}^{2}
$$

where: $\mathrm{K}_{2}\left(\mathrm{~g} \cdot \mathrm{mg}^{-1} \cdot \mathrm{min}^{-1}\right)$ is the pseudo-second-order rate constant and $\mathrm{S}_{\text {rate }}\left(\mathrm{mg} \cdot \mathrm{g}^{-1} \cdot \mathrm{min}^{-1}\right)$ is the initial adsorption rate.

\subsubsection{Vermeulen model}

The Vermeulen model is based on the assumption that intraparticle diffusion is the controlling mechanism of adsorption. It is also known as the Urano model or the Dumwald-Wagner model [33]. The integrated Vermeulen model can be expressed as

$$
q=q_{e}\left(1-e^{-B t}\right)
$$

An initial trial value for intraparticle diffusion constant $\mathrm{B}\left(\mathrm{min}^{-1}\right)$ may be obtained by using the relationship for the Vermeulen model

$$
B=\frac{\ln (4 / 3)}{t_{1 / 2}}
$$

Table 4 presents the parameters of the pseudo first-order, pseudo second order and intra-particle diffusion kinetic models. The pseudo-second order kinetic model (Figure 9) is the best to describe the $\mathrm{MB}$ adsorption mechanism on geopolymers $\mathrm{GP}_{0}$ and $\mathrm{GP}_{1}$ compared to the other 
kinetics models studied with the coefficients of determination $\left(\mathrm{R}^{2}\right)$ values are closest to unity and the model-predicted quantities of $\mathrm{MB}$ adsorbed $(19.521 \mathrm{mg} / \mathrm{g}$ and $24.073 \mathrm{mg} / \mathrm{g}$, respectively) are very close to those obtained experimentally $(22.858 \mathrm{mg} / \mathrm{g}$ and $24.473 \mathrm{mg} / \mathrm{g}$, respectively). The adsorption mechanism is thought to take place in the following sequence: diffusion of the solute molecule towards the surface of the geopolymers, followed by displacement of the solute towards the interior of the pores and finally fixation of the solute towards the active sites inside the pores [34]. It also reflects the existence of interactions between the surface of the adsorbent and the adsorbate, suggesting a multi-mechanistic chemisorption mechanism [35]. Noteworthy, the initial adsorption rate for MB uptake by $\mathrm{GP}_{1}$ was higher than $\mathrm{GP}_{0}$. The fast adsorption of $\mathrm{MB} \mathrm{GP}_{1}$ is attributed to the larger surface area of $\mathrm{GP}_{1}$ than $\mathrm{GP}_{0}$ resulting to easier and faster access to the binding sites in $\mathrm{GP}_{1}$. This reveals that the use of hydrogen peroxide as a blowing porogen during the synthesis modifies the textural properties (porosity and the specific surface area) but does not increase the identity of the binding sites as shown by the FTIR results.

Table 4: Parameters obtained from kinetic models

\begin{tabular}{|c|c|c|c|}
\hline Models & Parameters & $\mathbf{G P}_{0}$ & $\mathbf{G P}_{1}$ \\
\hline \multirow{6}{*}{ Pseudo first order } & $\mathrm{K}_{1}\left(\mathrm{~min}^{-1}\right)$ & 1.996 & 2.523 \\
\hline & $\mathrm{q}_{\mathrm{e}}(\mathrm{cal})\left(\mathrm{mg} \mathrm{g}^{-1}\right)$ & 18.550 & 24.069 \\
\hline & $\mathrm{q}_{\mathrm{e}}(\exp )\left(\mathrm{mg} \mathrm{g}^{-1}\right)$ & 22.858 & 24.473 \\
\hline & $\mathrm{t}_{1 / 2}(\min )$ & 0.347 & 0.275 \\
\hline & Srate $\left(\mathrm{mg} \cdot \mathrm{g}^{-1} \cdot \mathrm{min}^{-1}\right)$ & 37.030 & 60.726 \\
\hline & $\mathrm{R}^{2}$ & 0.852 & 0.998 \\
\hline \multirow{6}{*}{$\begin{array}{l}\text { Pseudo } \\
\text { order }\end{array}$} & $\mathrm{K}_{2}\left(\mathrm{~g} \mathrm{mg}^{-1} \mathrm{~min}^{-1}\right)$ & 0.039 & 9.999 \\
\hline & $\mathrm{q}_{\mathrm{e}}(\mathrm{cal})\left(\mathrm{mg} \mathrm{g}^{-1}\right)$ & 19.521 & 24.073 \\
\hline & $\mathrm{q}_{\mathrm{e}}(\exp )\left(\mathrm{mg} \mathrm{g}^{-1}\right)$ & 22.858 & 24.473 \\
\hline & $\mathrm{t}_{1 / 2}(\min )$ & 1.316 & 0.004 \\
\hline & Srate $\left(\mathrm{mg} \cdot \mathrm{g}^{-1} \cdot \mathrm{min}^{-1}\right)$ & 14.837 & 5794.644 \\
\hline & $\mathrm{R}^{2}$ & 0.858 & 0.998 \\
\hline
\end{tabular}




\begin{tabular}{llll}
\hline & $\mathrm{B}\left(\mathrm{min}^{-1}\right)$ & 3.216 & 3.216 \\
\cline { 2 - 4 } & $\mathrm{q}_{\mathrm{e}}(\mathrm{cal})\left(\mathrm{mg} \mathrm{g}^{-1}\right)$ & 18.551 & 24.069 \\
\cline { 2 - 4 } $\mathrm{q}_{\mathrm{e}}(\exp )\left(\mathrm{mg} \mathrm{g}^{-1}\right)$ & 22.858 & 24.473 \\
\hline Vermeulen & $\mathrm{t}_{1 / 2}(\min )$ & 0.0894 & 0.089 \\
\cline { 2 - 3 } & $\mathrm{R}^{2}$ & 0.852 & 0.998
\end{tabular}
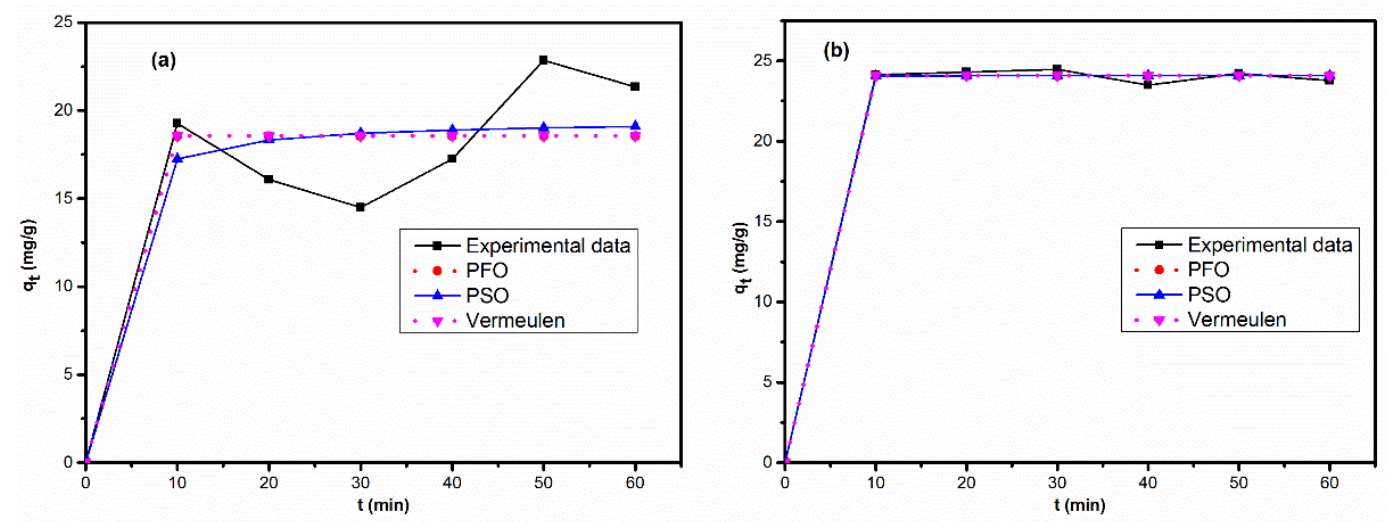

Figure-9: PFO, PSO and Vermeulen models applied to the experimental kinetic data for the adsorption of $\mathrm{MB}$ on different geopolymers ((a) $\mathrm{GP}_{0}$ and (b) $\left.\mathrm{GP}_{1}\right)$

\subsection{Influence of initial concentration}

From Figure 10, the quantities adsorbed in $\mathrm{MB}$ increase linearly with the initial $\mathrm{MB}$ concentrations of $4.71-21.35 \mathrm{mg} / \mathrm{g}$ and $4.89-23.78 \mathrm{mg} / \mathrm{g}$ for $\mathrm{GP}_{0}$ and $\mathrm{GP}_{1}$ materials, respectively. This observation implies that an increase in MB concentration increases the diffusion and fixation of the solute molecules within the pores of these geopolymers.

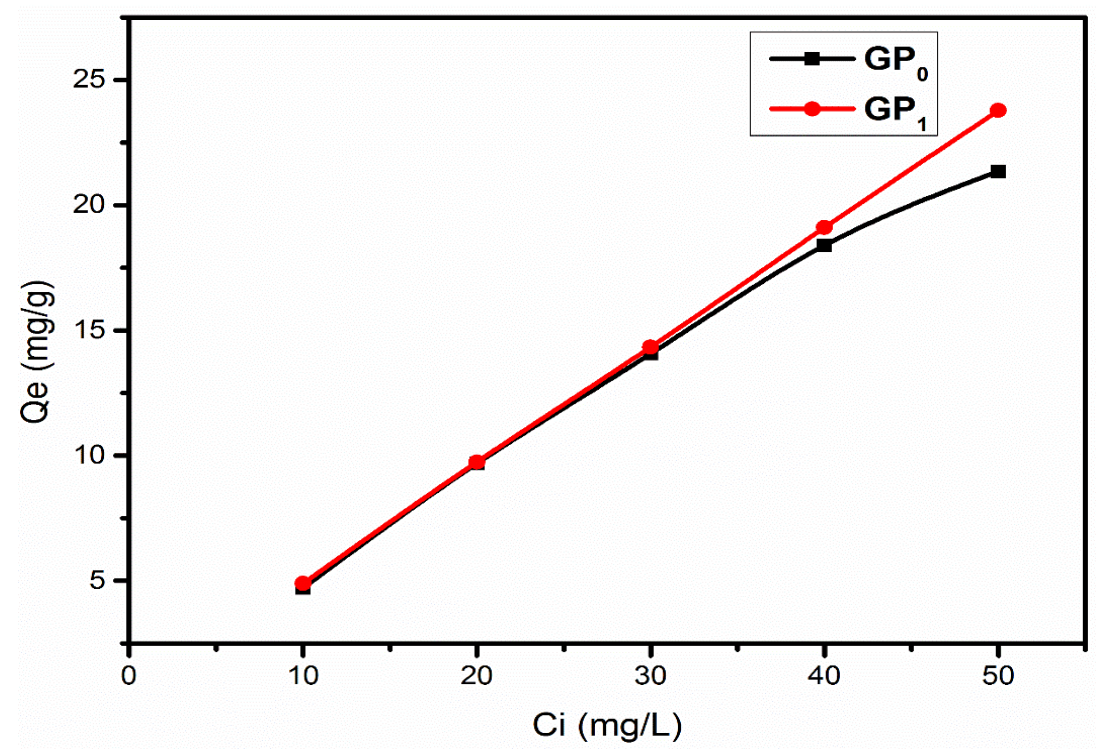


Figure 10: effect of initial concentration

\subsection{Isotherms adsorption}

Experimental equilibrium data were analyzed using five theoretical non-linear adsorption isotherms (Langmuir, Freundlich, Temkin, Dubinin-Radushkevich-Kaganer and Sips) to determine the model that best predicts the adsorption data and therefore best describes the adsorption mechanism of methylene blue on these eco-adsorbents.

\subsubsection{Langmuir Isotherm}

Langmuir isotherm (Langmuir, 1916) suggests a one-one association between adsorbate and adsorbent resulting in the formation of a monolayer. The adsorption data are validated by determining the uptake capacity $\left(\mathrm{q}_{\mathrm{e}}\right)$ and adsorption parameters using Eq. (12) where $\mathrm{q}_{\mathrm{e}}(\mathrm{mg} / \mathrm{g})$ is the amount adsorbed at equilibrium and $\mathrm{C}_{\mathrm{e}}(\mathrm{mg} / \mathrm{L})$ is the equilibrium concentration.

$$
q_{e}=\frac{Q_{m} K_{L} C_{e}}{1+K_{L} C_{e}}
$$

Where $q_{e}$ is the amount of $\mathrm{MB}$ adsorbed at equilibrium $\left(\mathrm{mg} \mathrm{g}^{-1}\right), C_{e}$ is the $\mathrm{MB}$ concentration in the aqueous phase at equilibrium $\left(\mathrm{mg} \mathrm{L}^{-1}\right), Q_{m}$ is the Langmuir maximum adsorption capacity $\left(\mathrm{mg} \mathrm{g}^{-1}\right)$ and $K_{L}$ is the Langmuir constant $\left(\mathrm{L} \mathrm{g}^{-1}\right)$. The dimensionless separation factor, $\mathrm{R}_{\mathrm{L}}$, was calculated using Eq. (13) [36]. The $\mathrm{R}_{\mathrm{L}}$ value indicates whether the adsorption is favorable $(0<$ $R L<1)$, unfavorable $\left(R_{L}>1\right)$, linear $\left(R_{L}=1\right)$, or irreversible $\left(R_{L}=0\right)$ [34].

$$
R_{L}=\frac{1}{1+K_{L} C_{0}}
$$

\subsubsection{Freundlich Isotherm}

The Freundlich isotherm model (Freundlich, 1906) is an empirical equation that is applied to multilayer adsorption. This model assumes that the surface of the adsorbent is heterogeneous and active sites and their energies distribute exponentially. The Freundlich isotherm is expressed as Eq. (14):

$$
q_{e}=K_{F} C_{e}^{1 / n}
$$

Where $K_{F}$ is the Freundlich constant $\left(\mathrm{L} \mathrm{g}^{-1}\right)$ and the parameter $n$ is a dimensionless constant.

\subsubsection{Dubinin-Radushkevich Kaganer isotherm}


The Dubinin-Radushkevich-Kaganer (D-R-K) isotherm (Eq.15) is applied to the adsorption process onto a microporous adsorbent. It estimates the energy of adsorption and distinguishes between physisorption or chemisorption nature of adsorption onto homogeneous and heterogeneous surfaces [36].

$Q_{e}=Q_{m} \exp \left(-\beta \xi^{2}\right)$

Where $\mathrm{Q}_{\mathrm{e}}$ is the amount of adsorbate adsorbed per unit dosage of the adsorbent at equilibrium $\left(\mathrm{mol} / \mathrm{g}\right.$ ) and $\mathrm{Q}_{\mathrm{m}}$ is the theoretical monolayer saturation capacity (mol/g) [37]. The Polanyi potential $(\varepsilon)$ is expressed as

$\xi=R T \ln \left(1+\frac{1}{c_{e}}\right)$

The mean sorption energy $E_{a}(\mathrm{~kJ} / \mathrm{mol})$ of the adsorbate (Eq.17) identifies the physical and chemical interactions between the adsorbate and adsorbent during the adsorption process. $E_{a}=\frac{1}{\sqrt{2 \beta}}$

\subsubsection{Temkin isotherm}

The Temkin isotherm model contains a factor that explicitly takes into account the adsorbentadsorbate interactions. The heat of adsorption of all the molecules in the layer would decrease linearly with coverage due to adsorbent-adsorbate interactions. The adsorption is characterized by a uniform distribution of binding energies, up to some maximum binding energy. The Temkin adsorption isotherm expression is shown in Eq. (18) [38].

$q_{e}=B_{T} \ln \left(A_{T} C_{e}\right)$

Where $\mathrm{B}_{\mathrm{T}}=\mathrm{RT} / \mathrm{b}_{\mathrm{T}}, \mathrm{b}(\mathrm{J} / \mathrm{mol})$ is the Temkin constant relating to the heat of sorption; $\mathrm{A}(\mathrm{L} / \mathrm{g})$ is the Temkin isotherm constant. $\mathrm{R}$ is the universal gas constant $(8.314 \mathrm{~J} / \mathrm{mol} . \mathrm{K})$, and $\mathrm{T}(\mathrm{K})$ the absolute temperature.

\subsubsection{Sips isotherm}

By identifying the problem of continuing increase in the adsorbed amount with an increase in concentration in the Freundlich equation, Sips proposed an equation that combines the Freundlich and Langmuir isotherms. This produces an expression that exhibits a finite limit at sufficiently high concentration. This model is valid for predicting the heterogeneous adsorption systems and localized adsorption without adsorbate-adsorbate interactions. The Sips isotherm model is given by Eq. (19): 
$Q_{e}=\frac{Q_{m s} a_{s} C_{e}^{B_{s}}}{1+a_{s} C_{e}^{B_{s}}}$

Where $Q_{m s}, a_{s}$ and $B_{s}$ are the isotherm constants. The constant $\mathrm{B}_{\mathrm{s}}$ is the heterogeneity index.

The assessment of the validity of the results in Table 5 was based on the values of the coefficient of determination, $\mathrm{R}^{2}$. The equilibrium data was described by the models in the order Sips $>$ Temkin > Langmuir > D-K-R > Freundlich model for the $\mathrm{GP}_{0}$ and Freundlich > Sips $>$ Langmuir > Temkin > D-K-R model for the material GP ${ }_{1}$.

The Freundlich isotherm is appropriate to describe the adsorption mechanism of MB on the geopolymer $\mathrm{GP}_{1}$ and the value of the Freundlich parameter $n$ lower than 1 , implies that the adsorption sites of this geopolymer are heterogeneous, consequently the adsorption is carried out in multilayer and the isotherm is linear of $\mathrm{H}$ type (Figure 12b) [39].

The Sips isotherm, was the most appropriate to describe the adsorption of MB on geopolymer $\mathrm{GP}_{0}$. The heterogeneity factor (Bs) of 1.14893 greater than unity, indicates a heterogeneity of the system resulting from the interaction adsorbent-adsorbate [40]. The adsorption capacities can be estimated using the sips isotherm model, therefore it follows that the adsorption capacity of $\mathrm{MB}$ are high on the $\mathrm{GP}_{1}(366.196 \mathrm{mg} / \mathrm{g})$ that $\mathrm{GP}_{0}(24.440 \mathrm{mg} / \mathrm{g})$. This could be justified simply by the high pore volume and specific surface area that $\mathrm{GP}_{1}$ has compared to $\mathrm{GP}_{0}($ Table 2). The high adsorption capacity of $\mathrm{MB} \mathrm{GP}_{1}$ material (15 times higher than that of $\mathrm{GP}_{0}$ material) is also justified by the various phenomena possibly taking place within the multiple pores (Figure 11) such as:

- Electrostatic interactions between the negative sites of geopolymers and positives sites of MB.

- $\quad$ Ions exchange between the MB cations and counter ions $\left(\mathrm{Na}^{+}, \mathrm{K}^{+}, \mathrm{Ca}^{2+}\right.$ and $\left.\mathrm{Mg}^{2+}\right)$.

- Formation of dative bonds between the nitrogen doublets of MB molecules and the empty quantum cells of the $\mathrm{GP}_{1}$ material. 


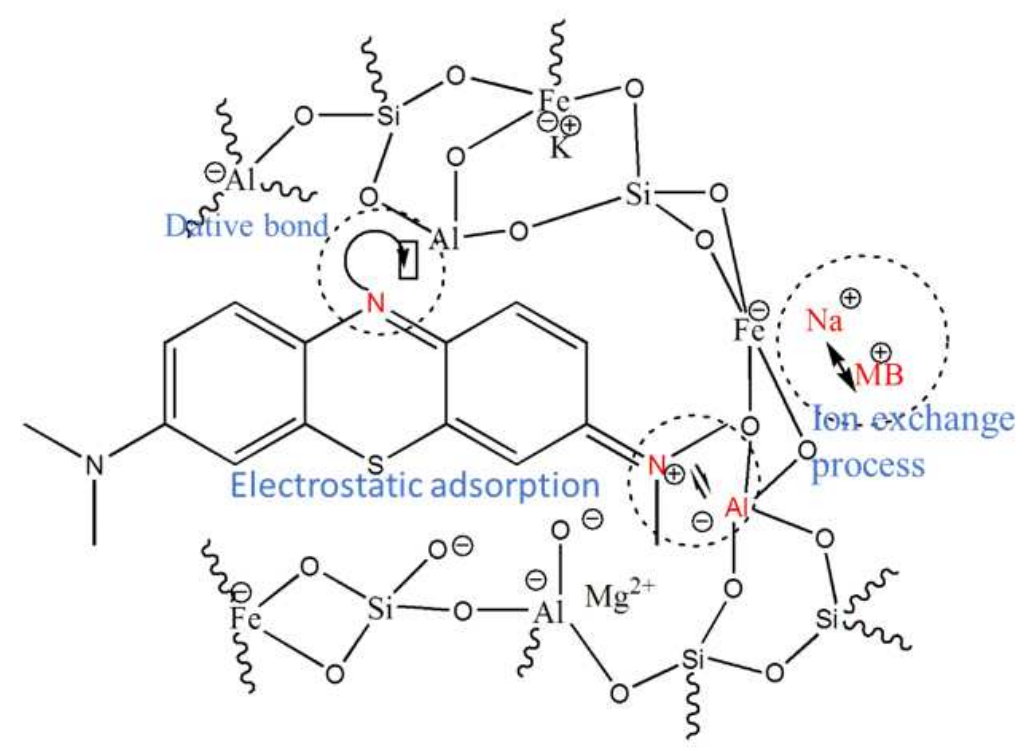

Figure 11: Interaction mechanisms in the GP1-MB system.

The D-R -K model shows that the adsorption energy of the two synthetic materials is less than $8 \mathrm{~kJ} / \mathrm{mol}$ which suggests that physisorption is the dominant adsorption mechanism [41].

Table 5: Parameters obtained from adsorption isotherms

\begin{tabular}{|c|c|c|c|}
\hline Isotherms & Parameter & $\mathrm{GP}_{0}$ & $\mathrm{GP}_{1}$ \\
\hline \multirow{4}{*}{ Langmuir } & $\mathrm{Q}_{\max }(\mathrm{mg} / \mathrm{g})$ & 23.897 & 30.102 \\
\hline & $\mathrm{K}_{\mathrm{L}}(\mathrm{L} / \mathrm{mg})$ & 0.915 & 0.838 \\
\hline & $\mathrm{R}_{\mathrm{L}}$ & 0.021 & 0.023 \\
\hline & $\mathrm{R}^{2}$ & 0.917 & 0.981 \\
\hline \multirow{3}{*}{ Freundlich } & $\mathrm{K}_{\mathrm{F}}(\mathrm{mg} / \mathrm{g})(\mathrm{L} / \mathrm{mg})^{-1}$ & 10.183 & 13.242 \\
\hline & $1 / \mathrm{n}$ & 0.403 & 0.627 \\
\hline & $\mathrm{R}^{2}$ & 0.884 & 0.982 \\
\hline \multirow{3}{*}{$\mathrm{D}-\mathrm{R}-\mathrm{K}$} & $\mathrm{Q}_{\max }(\mathrm{mg} / \mathrm{g})$ & 20.181 & 22.076 \\
\hline & $\mathrm{E}_{\mathrm{a}}(\mathrm{KJ} / \mathrm{mol})$ & 1.036 & 1.374 \\
\hline & $\mathrm{R}^{2}$ & 0.907 & 0.873 \\
\hline \multirow{3}{*}{ Temkin } & A (L/g) & 5.692 & 8.215 \\
\hline & $\Delta \mathrm{Q}(\mathrm{KJ} / \mathrm{mol})$ & 5.953 & 7.152 \\
\hline & $\mathrm{R}^{2}$ & 0.933 & 0.936 \\
\hline
\end{tabular}




\begin{tabular}{|c|c|c|c|}
\hline \multirow{4}{*}{ Sips } & $\mathrm{Q}_{\max }(\mathrm{mg} / \mathrm{g})$ & 24.440 & 366.196 \\
\hline & as & 0.730 & 0.038 \\
\hline & $\mathrm{B}_{\mathrm{S}}$ & 1.1489 & 0.652 \\
\hline & $\mathrm{R}^{2}$ & 0.941 & 0.981 \\
\hline
\end{tabular}
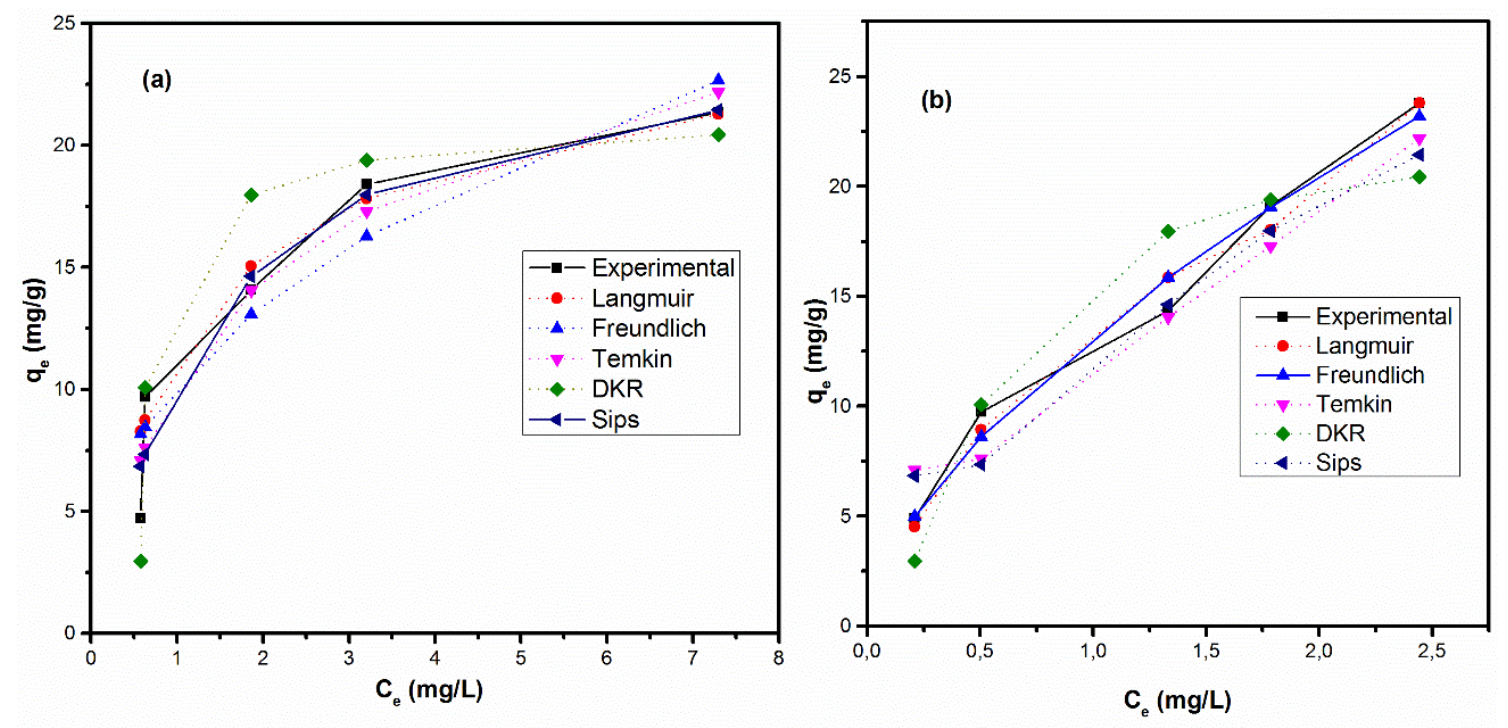

Figure 12: Adsorption isotherm plots for $\mathrm{MB}$ onto (a) $\mathrm{GP}_{0}$ and (b) $\mathrm{GP}_{1}$ materials

\subsection{Adsorption thermodynamics}

The effect of temperature and adsorption thermodynamics functions were evaluated in the temperature range 309-339 K. The thermodynamic functions, enthalpy change $(\Delta \mathrm{H})$, Gibb's free energy $(\Delta \mathrm{G})$, and entropy $(\Delta \mathrm{S})$ were calculated using equations 20-23 and the calculated parameters for MB uptake are listed in Table 6.

$\Delta G=-R T \ln K_{c}$

$K_{d}=\frac{C_{a d s}}{C_{e}}$

$K_{c}=1000 K_{d}$

$\ln K_{c}=\frac{\Delta S}{R}-\frac{\Delta H}{R} \frac{1}{T}$

Where $K_{c}$ is the equilibrium constant (dimensionless), $C_{e}$ is the residual dye concentration in the aqueous phase at equilibrium $\left(\mathrm{mg} \mathrm{L}^{-1}\right)$ and $C_{a d s}$ is the dye concentration in the adsorbent at 
equilibrium ( $\left.\mathrm{mg} \mathrm{g}^{-1}\right), \mathrm{K}_{\mathrm{d}}$ is the distribution coefficient $(\mathrm{L} / \mathrm{g})$ and the density of water is 1000 $\mathrm{g} / \mathrm{L}$. $\mathrm{R}$ is the gas constant $\left(8.314 \mathrm{~J} \mathrm{~mol}^{-1} \mathrm{~K}^{-1}\right)$ and $\mathrm{T}$ is the temperature $(\mathrm{K})$.

The positive enthalpy $(\Delta \mathrm{H})$ values confirm that adsorption of the MB on the eco-adsorbents is an endothermic reaction. The negative $\Delta \mathrm{G}$ values, reveal the feasibility and spontaneity of $\mathrm{MB}$ removal on both geopolymers. The decrease in the magnitude of $\Delta \mathrm{G}$ with rise in temperature imply the reaction becomes more and more spontaneous and the amount adsorbed increases with increased temperature consistent with an endothermic process (Figure 13). The relatively low $\Delta \mathrm{G}$ values correspond to a physical process. The positive values of entropy denote that the approach and distribution of $\mathrm{MB}$ molecules through the pores of $\mathrm{GP}_{0}$ and $\mathrm{GP}_{1}$ materials is disordered. In addition, the $\Delta \mathrm{H}$ values below $40 \mathrm{~kJ} \mathrm{~mol}^{-1}$ indicate that the sorption of $\mathrm{MB}$ on these eco-adsorbents entails a physisorption mechanism, consistent with the prediction from DK-R model [42].

Table 6: Thermodynamic functions for MB uptake by $\mathrm{GP}_{0}$ and $\mathrm{GP}_{1}$

\begin{tabular}{|c|c|c|c|c|}
\hline Adsorbent & $\begin{array}{l}\text { Temp. } \\
\text { (K) }\end{array}$ & $\begin{array}{l}\Delta G \\
\left(\mathrm{~kJ} \mathrm{~mol}^{-1}\right)\end{array}$ & $\begin{array}{c}\Delta \mathbf{H} \\
\left(\mathrm{kJ} \mathrm{mol}^{-1}\right)\end{array}$ & $\begin{array}{c}\Delta \mathrm{S} \\
\left(\mathrm{kJ} \mathrm{mol}^{-1}\right)\end{array}$ \\
\hline & 309 & -16.02 & & \\
\hline & 319 & -16.66 & & \\
\hline \multirow[t]{4}{*}{$\mathbf{G P}_{0}$} & 329 & -17.92 & 32.20 & 0.15 \\
\hline & 339 & -20.84 & & \\
\hline & 309 & -17.49 & & \\
\hline & 319 & -18.91 & & \\
\hline \multirow[t]{2}{*}{ GP1 } & 329 & -19.81 & 20.62 & \\
\hline & 339 & -21.31 & & 0.12 \\
\hline
\end{tabular}




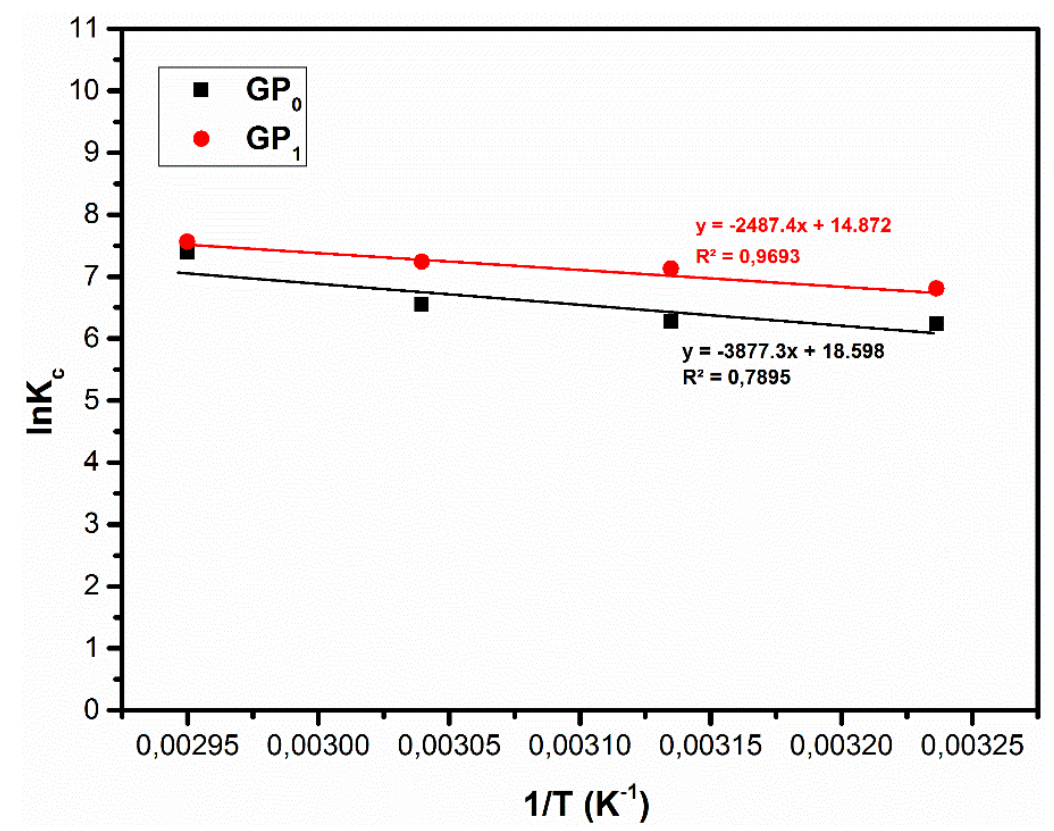

Figure 13: Isotherm plot of van't Hoff.

\section{Conclusion}

The development the pozzolan-based eco-adsorbents was done by geopolymerization using hydrogen peroxide as a blowing agent with mass ratios 0 and $1 \%$, labeled $\mathrm{GP}_{0}$ and $\mathrm{GP}_{1}$ respectively, in order to modify the textural properties and to evaluate their performance in removing the basic dye methylene blue in aqueous solution. The physico-chemical characteristics revealed that the incorporation of $1 \%$ blowing agent increased the specific surface are from 4.344 to $5.610 \mathrm{~m}^{2} / \mathrm{g}$. The increase in surface area resulted to an increase in adsorption capacity by 15 orders of magnitude from 24.4 to $366.2 \mathrm{mg} / \mathrm{g}$ for $\mathrm{GP}_{0}$ and $\mathrm{GP}_{1}$, respectively. The adsorption rates of methylene blue on the two eco-adsorbents were best described by the pseudo-second order kinetic model. The adsorption equilibrium data were best described by the Sips and Freundlich isotherms models for $\mathrm{GP}_{0}$ and $\mathrm{GP}_{1}$, respectively. Thermodynamically, it was determined that the adsorption of methylene blue onto ecoadsorbents is a physical and endothermic process. The results show that incorporation of hydrogen peroxide into pozzolan-based geopolymers increases their adsorption capacity for methylene blue dye stupendously relative under the experimental conditions reported.

\section{Acknowledgements}

We thank Institute of Inorganic chemistry and structural in Dusseldorf (Germany) for the characterization of raw materials and geopolymers samples.

\section{Author Contributions}


David Dina, Sylvain Tome: Validation, Methodology, Writing - review \& editing,

Visualization, original draft. Dzoujo T. Hermann, Jean T. Tchuigwa: Conceptualization, Methodology, Investigation, writing - original draft, resources. Victor O. Shikuku: Validation, Writing - review \& editing. Alex Spieß: Validation, Writing - review \& editing, Marie-Annie Etoh: Writing - review \& editing, Visualization. David Dina, Marie-Annie Etoh, Christoph Janiak: Resources, Supervision

\section{Funding}

The authors of manuscript did not receive any funding and grants for this work.

\section{Availability of data and materials}

All data generated or analyzed during this study are included in this article.

\section{Compliance with ethical standards}

\section{Conflict of interest}

The authors declare that they have no conflict of interest.

\section{Consent to participate}

Not Applicable

\section{Consent for publication}

Not Applicable

\section{References}

1. Fatima Zohra Choumane, (2015) Elimination des métaux lourds et pesticides en solution aqueuse par des matrices argileuses, Thèse de Doctorat, Chimie de l'environnement.

2. Taylor, Publisher, Mark A. Brown, and Stephen C. De Vito. (2009) "Critical Reviews in Environmental Science and Technology Predicting Azo Dye Toxicity Predicting Azo Dye Toxicity." (June 2013):37-41.

3. Ghosh, Dipa, and Krishna G. Bhattacharyya. (2002) “Adsorption of Methylene Blue on Kaolinite.” 20:295-300.

4. ALVARES A.B.C., C. DLAPER et S.A. PARSONS. (2013) Partial oxidation by ozone to remove recalcitrance from wastewaters - a review. Environ. Technol., 22, 409-427

5. Badawi, M. A., N. A. Negm, M. T. H. Abou Kana, H. H. Hefni, and M. M. Abdel Moneem.(2017). “Adsorption of Aluminum and Lead from Wastewater by ChitosanTannic Acid Modified Biopolymers: Isotherms, Kinetics, Thermodynamics and Process Mechanism." International Journal of Biological Macromolecules.doi: 10.1016/j.ijbiomac.2017.03.003. 
6. Sharma, P., Kaur, H., Sharma, M., \& Sahore, V. (2011) A review on applicability of naturally available adsorbents for the removal of hazardous dyes from aqueous waste 151-195. https://doi .org/10.1007/s10661-011-1914-0

7. US Department of the interior and US Geological Survey (2010). Minerals yearbook, metals and minerals, vol 1. Government Printing Office,Washington DC.

8. Billong N, Melo UC, Njopwouo N, Louvet F, Bonnet JP. (2013) Physicochemical characteristics of Some Cameroonian pozzolans for use in sustainable cement like materials. Mater Sci Appl 4:14-21.

9. Wamba, A. G. N., Lima, E. C., Ndi, S. K., Thue, P. S., Kayem, J. G., Rodembusch, F. S., dos Reis, G. S., \& de Alencar, W. S. (2017) Synthesis of grafted natural pozzolan with 3 aminopropyltriethoxysilane: preparation, characterization, and application for removal of Brilliant Green 1 and Reactive Black 5 from aqueous solutions. Environmental Science and Pollution Research, 24(27), 21807-21820. .

10. Kofa, G. P., S. NdiKoungou, G. J. Kayem, and R. Kamga . (2015) “Adsorption of Arsenic by Natural Pozzolan in a Fixed Bed: Determination of Operating Conditions and Modeling." Journal of Water Process Engineering 6:166-73. doi: 10.1016/j.jwpe.2015.04.006.

11. Gaston Fumba, Jean Serge Essomba, Guy Merlain Tagne, Julius Ndi Nsami, Placide Désiré Bélibi Bélibi and Joseph Ketcha Mbadcam. (2014) Equilibrium and Kinetic Adsorption Studies of Methyl Orange from Aqueous Solutions Using Kaolinite, Metakaolinite and Activated Geopolymer as Low Cost Adsorbents, Journal of Academia and Industrial Research (JAIR)Volume 3, 156-163.

12. Novais, R.M., Ascensão, G., Tobaldi, D.M., Seabra, M.P., Labrincha, J.A. (2018) Biomass Fly ash geopolymer monoliths for effective methylene blue removal from wastewaters. J. Clean. Prod., 171, 783794.

13. Marouane, E., Saliha, A., Mohammed, E., Taibi, M. (2019) Preparation, Characterization, and Application of Metakaolin-Based Geopolymer for Removal of Methylene Blue from Aqueous Solution. J. Chem. https://doi.org/10.1155/2019/4212901.

14. Bai, Chengying, and Paolo Colombo. (2018) "Processing, Properties and Applications of Highly Porous Geopolymers: A Review.” Ceramics International 44(14):16103-18. doi:10.1016/j.ceramint.2018.05.219. 
15. Singhal, Aditi; Gangwar, Bhanu P.; Gayathry, J.M. (2017). CTAB modified large surface area nanoporous geopolymer with high adsorption capacity for copper ion removal. Applied Clay Science, 150(), 106-114.doi:10.1016/j.clay.2017.09.013

16. Sarkar, Chayan; Basu, Jayanta Kumar; Samanta, Amar Nath (2018). Experimental and kinetic study of fluoride adsorption by Ni and Zn modified LD slag based Geopolymer. Chemical Engineering Research and Design, S0263876218306221-. doi:10.1016/j.cherd.2018.12.006

17. Runtti, Hanna; Luukkonen, Tero; Niskanen, Mikko; Tuomikoski, Sari; Kangas, Teija; Tynjälä, Pekka; Tolonen, Emma-Tuulia; Sarkkinen, Minna; Kemppainen, Kimmo; Rämö, Jaakko; Lassi, Ulla (2016). Sulphate removal over barium-modified blastfurnace-slag geopolymer. Journal of Hazardous Materials, S0304389416305568-. doi:10.1016/j.jhazmat.2016.06.001

18. M. Sido-Pabyam, M. Gueye, J. Blin, E. Some (2009). Valorisation de résidus de Biomasse en Charbons actifs - Tests d'efficacité sur des bactéries et dérivés de pesticides. Revue Sud Sciences et Technologies, 17, 65-73.

19. Karadag, Dogan (2007). "Modeling the Mechanism, Equilibrium and Kinetics for the Adsorption of Acid Orange 8 onto Surfactant-Modified Clinoptilolite : The Application of Nonlinear Regression Analysis.” 74. doi: 10.1016/j.dyepig.2006.04.009.

20. Davidovits, J. (2008) Geopolymer Chemistry \& Applications. Geopolymer Institute, Saint-Quentin.

21. Siyal, A. A., Shamsuddin, M. R., Khan, M. I., Rabat, E., Zulfiqar, M., Man, Z., Siame, J., \& Azizli, K. A. (2018) A Review on Geopolymers as Emerging Materials for the. Journal of Environmental Management. https://doi.org/10.1016/j.jenvman.2018.07.046

22. Sangwichien, C., G. L. Aranovich, and M. D. Donohue (2002). "Density Functional Theory Predictions of Adsorption Isotherms with Hysteresis Loops.” 206:313-20.

23. Khan, M. I., Min, T. K., Azizli, K., Sufian, S., Ullah, H., \& Man, Z. (2015) Effective removal of methylene blue from water using phosphoric acid based geopolymers:Synthesis, characterizations and adsorption studies. RSC Advances, 5(75), 61410-61420. https://doi.org/10.1039/c5ra08255b.

24. Tahir S.S. and Naseem Rauf (2006). Removal of cationic dye from aqueous solutions by adsorption onto bentonite clay. Chemosphere.63, 1842-1848 Ceramics International, 44(14), 16103-16118. https://doi.org/10.1016/j. ceramint.2018.05.219

25. Panias, Dimitrios, Ioanna P. Giannopoulou, and Theodora Perraki (2007). "Effect of 
Synthesis Parameters on the Mechanical Properties of Fly Ash-Based Geopolymers." 301:246-54. doi: 10.1016/j.colsurfa.2006.12.064.

26. Maragkos, Ioannis, Ioanna P. Giannopoulou, and Dimitrios Panias (2009). "Synthesis of Ferronickel Slag-Based Geopolymers.” 22:196-203. doi: 10.1016/j.mineng.2008.07.003.

27. Rattanasak, Ubolluk, and Prinya Chindaprasirt (2009). "Influence of $\mathrm{NaOH}$ Solution on the Synthesis of Fly Ash Geopolymer." Minerals Engineering 22(12):1073-78. doi: 10.1016/j.mineng.2009.03.022.

28. Tome, S., Etoh, M., Etame, J., \& Kumar, S. (2020) Improved Reactivity of Volcanic Ash using Municipal Solid Incinerator Fly Ash for Alkali-Activated Cement Synthesis. Waste and Biomass Valorization, 11(6), 3035-3044. https://doi.org/10.1007/s12649019-00604-1

29. Karim, A. B., Mounir, B., Hachkar, M., Bakasse, M., \& Yaacoubi, A. (2010) Élimination du colorant basique «Bleu de Méthylène » en solution aqueuse par l'argile de Safi. Revue Des Sciences de l'eau, 23(4), 375-388 .https://doi.org/10.7202/045099ar

30. Dotto, G. L., J. M. N. Santos, I. L. Rodrigues, R. Rosa, F. A. Pavan, and E. C. Lima. “Adsorption of Methylene Blue by Ultrasonic Surface Modified Chitin." JOURNAL OF COLLOID AND INTERFACE SCIENCE (2015). doi: 10.1016/j.jcis.2015.01.046.

31. Shikuku, V. O., Kowenje, C. O., \& Kengara, F. O. (2018) Errors in Parameters Estimation Using Linearized Adsorption Isotherms : Sulfadimethoxine Adsorption onto Kaolinite Clay. 23(4), 1-6. https://doi.org/10.9734/CSJI/2018/44087

32. Yao, C., \& Chen, T. (2019) An improved regression method for kinetics of adsorption from aqueous solutions. Journal of Water Process Engineering, 31(May), 100840. https://doi.org/10.1016/j.jwpe.2019.100840

33. G. McKay, M.S. Otterburn, J.A. Aga. (1985) Fuller's earth and fired clay as adsorbents for dyestuffs, Water, Air, Soil Pollut. 24, 307-322.

34. Ofomaja, Augustine E. (2008) "Sorptive Removal of Methylene Blue from Aqueous Solution Using Palm Kernel Fibre: Effect of Fibre Dose." 40:8-18. doi: 10.1016/j.bej.2007.11.028.

35. Mariame Conde Asseng, Hermann Tamaguelon Dzoujo, Daniel David Joh Dina, Marie Annie Etoh, Armand Ngoungue Tchakounte, and Julius Ndi Nsami (2020). "Batch Studies for the Removal of a Hazardous Azo Dye Methyl Orange from Water through Adsorption on Regenerated Activated Carbons." Journal of Materials Science and Engineering B 10(3):109-23. doi: 10.17265/2161-6221/2020.5-6.003. 
36. Itodo AU, Itodo HU. (2010) Sorption energies estimation using Dubinin Radushkevich and Temkin adsorption isotherms. Life Sci 7:31-39.

37. Jia, L. I. U., Wang Hong-liang, L. Ü. Chun-xin, L. I. U. Han-fei, G. U. O. Zhi-xin, and Kang Chun-li (2013). "Water Through Modified Diatomite." 29(2007):3-6. doi: 10.1007/s40242-013-2504-1.

38. M.I. Temkin, V. Pyzhev (1940). Kinetics of ammonia synthesis on promoted iron catalyst, Acta Physiochim. URSS 12, 327-356.

39. Freundlich H. (1906) on adsorption in solution. Z. Physik. Chem., vol. 57, pp385-471.

40. R. Sips (1948), on the structure of a catalyst surface, J. Chem. Phys., 16, 490.

41. Anagho S., Tchuifon R., Ndifor-Angwafor G., Ndi J., Ketcha J., Nchare M. (2013) "Nickel adsorption from aqueous solution onto kaolinite and metakaolinite: kinetic and equilibrium studies." International Journal of Chemistry, 4, 1-7.

42. Shikuku V.O., and Kimosop, J. (2020) efficient removal of sulfamethoxazole onto sugarcane bagasse-derived biochar: two and three-parameter isotherms, kinetics and thermodynamics. S. Afr. J. Chem., 73, 111-119. 
Figures

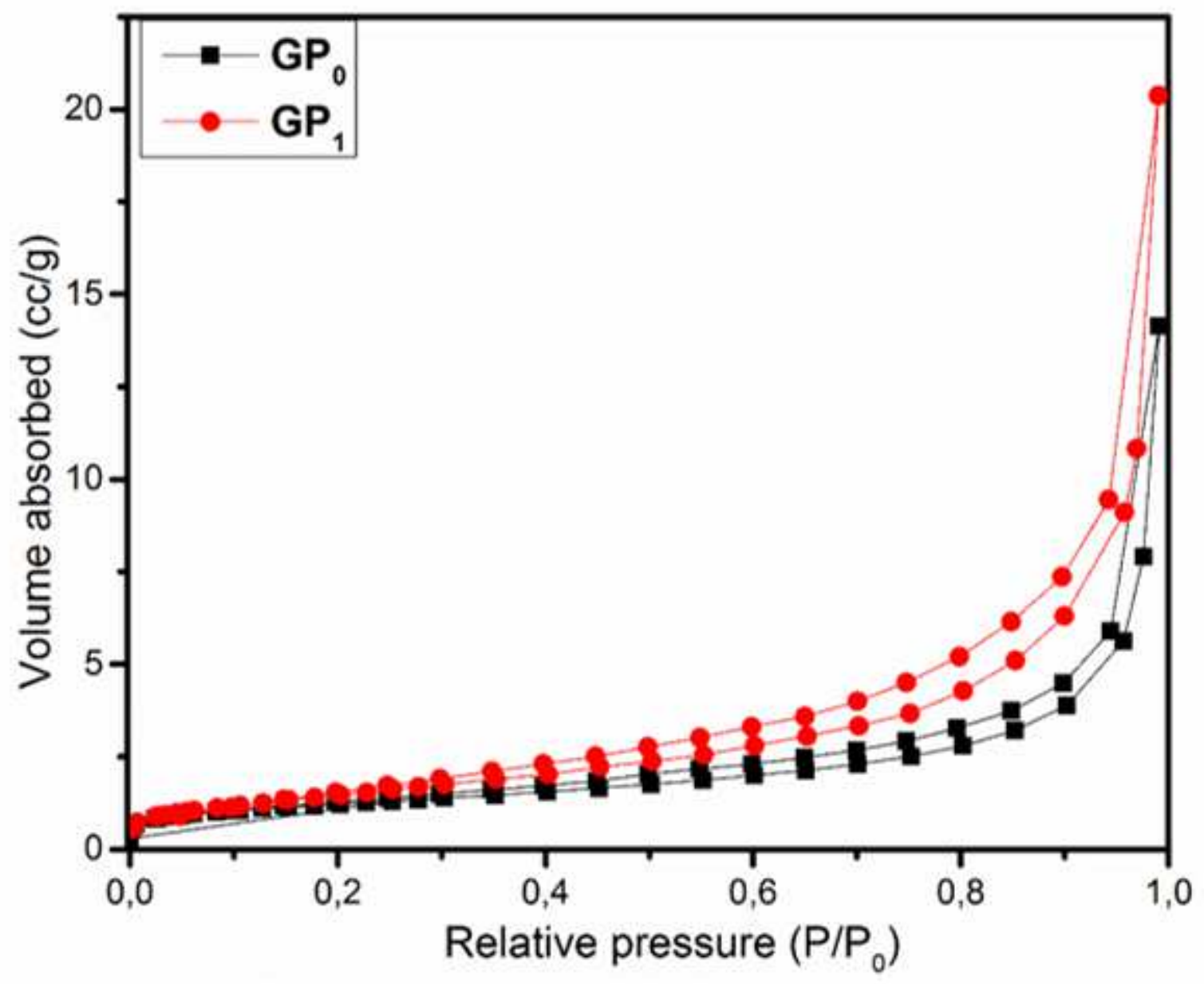

Figure 1

N2 adsorption-desorption isotherms of eco-adsorbents materials 


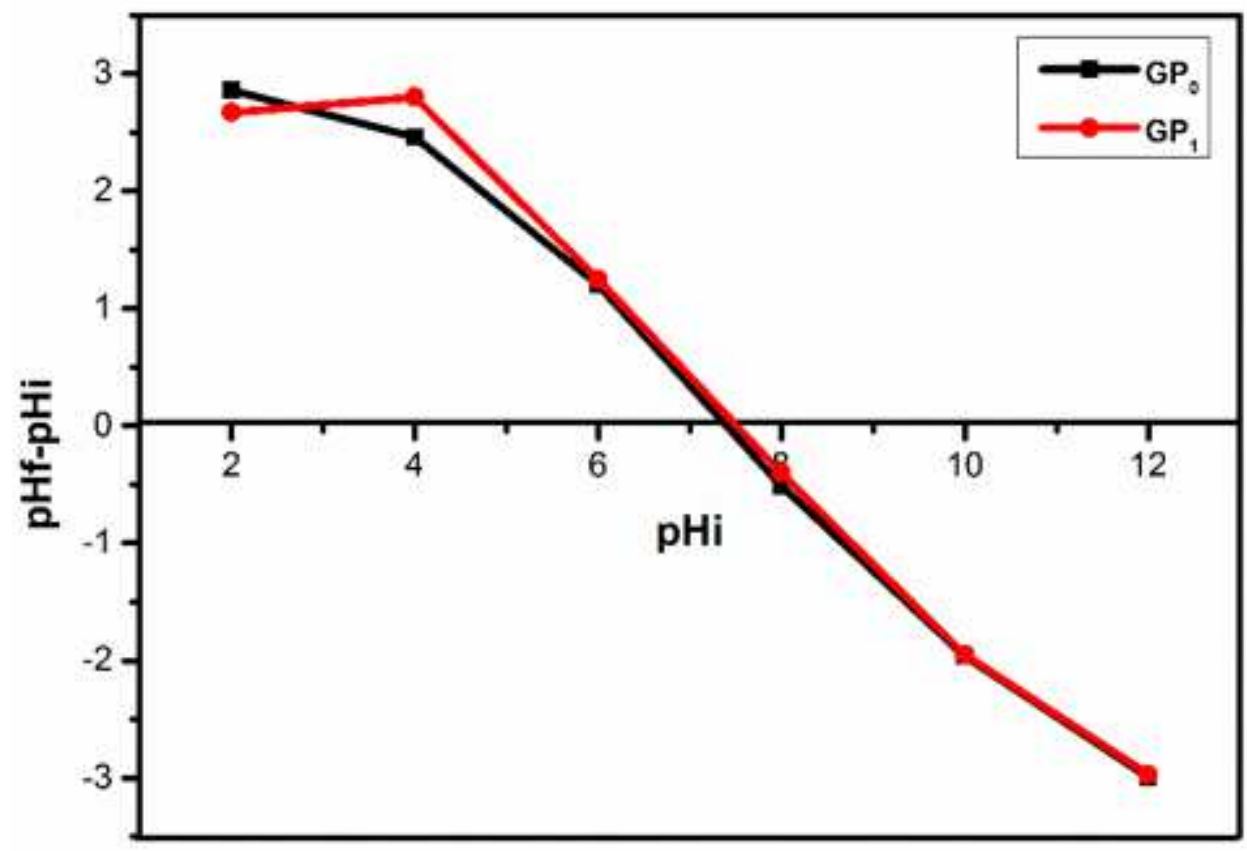

Figure 2

Point of Zero Charge of geopolymer materials. 


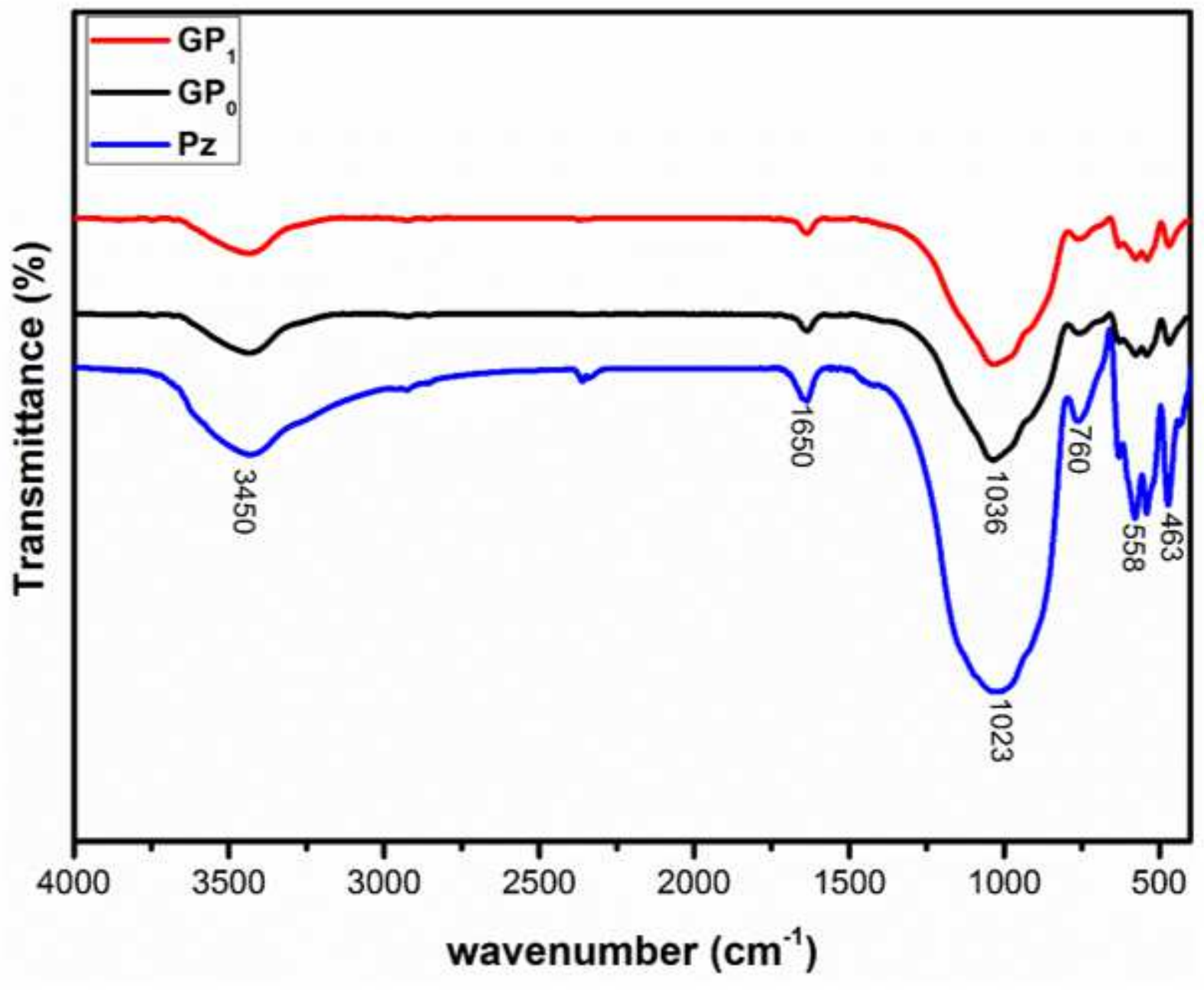

Figure 3

FTIR of the samples Pz, GP0 and GP1 


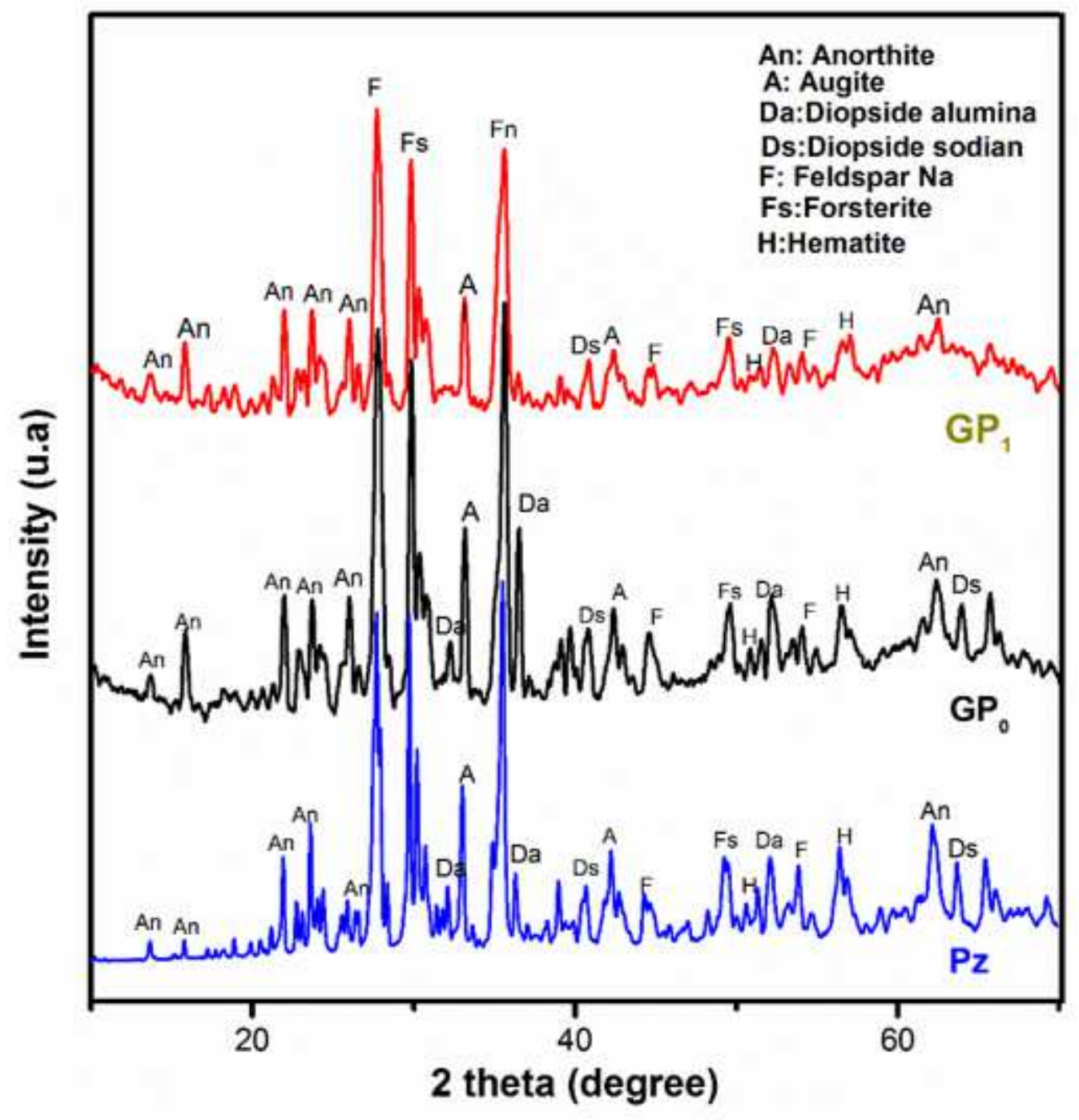

Figure 4

XRD patterns of precursor and GP0 and GP1 geopolymer 

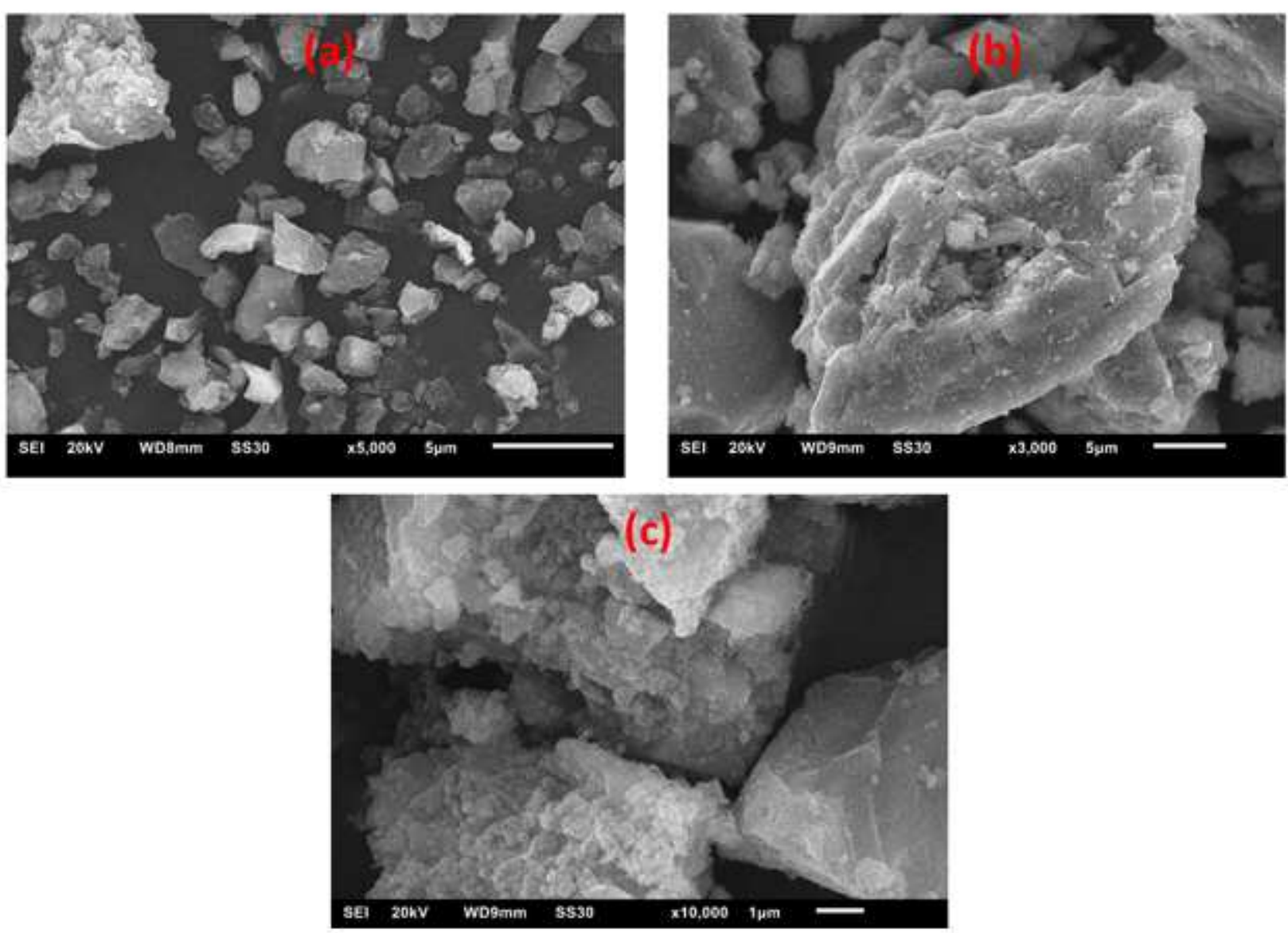

\section{Figure 5}

XRD patterns of precursor and GP0 and GP1 geopolymer 


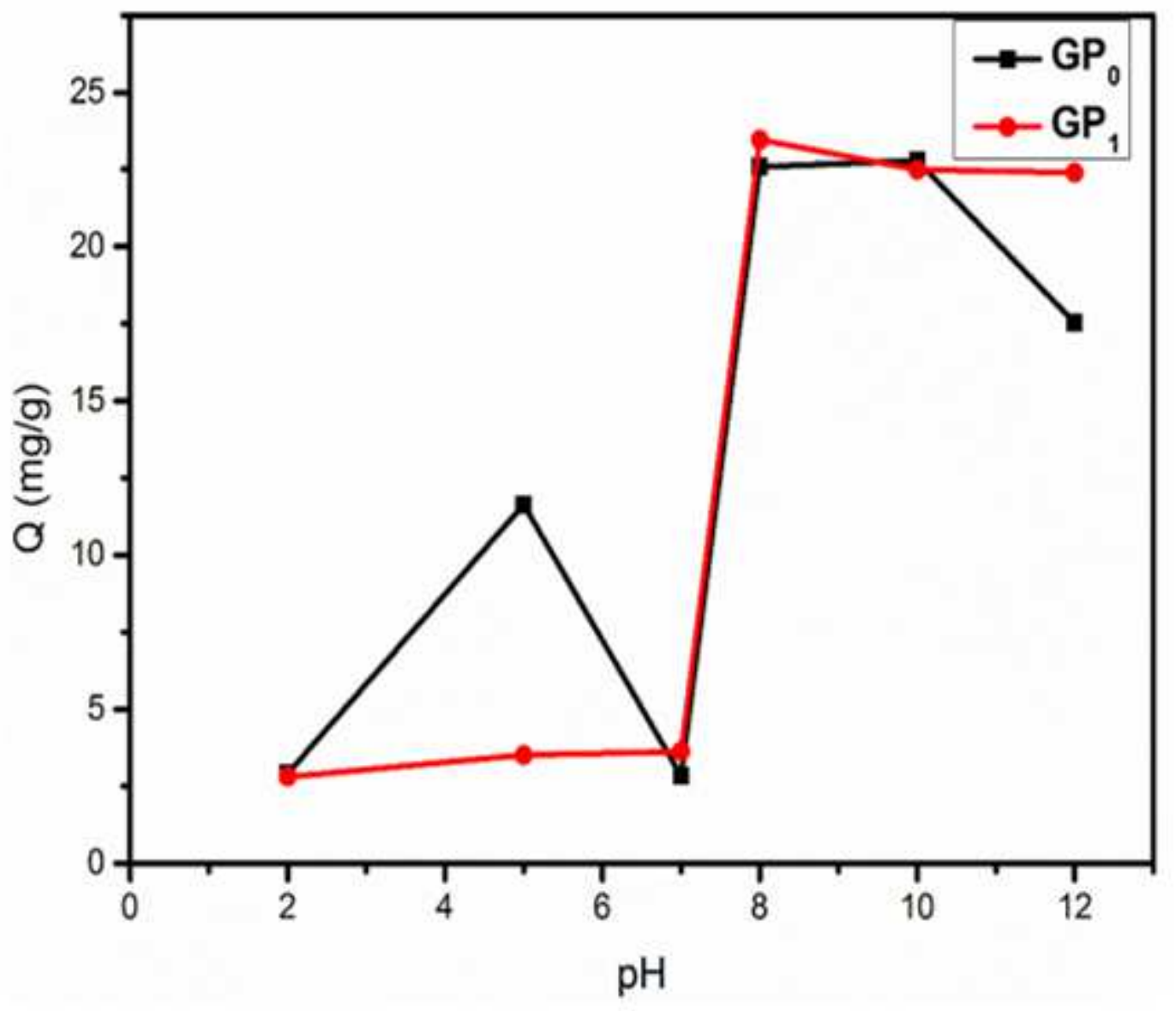

Figure 6

Influence of $\mathrm{pH}$ on the adsorption capacity of the different geopolymers. 


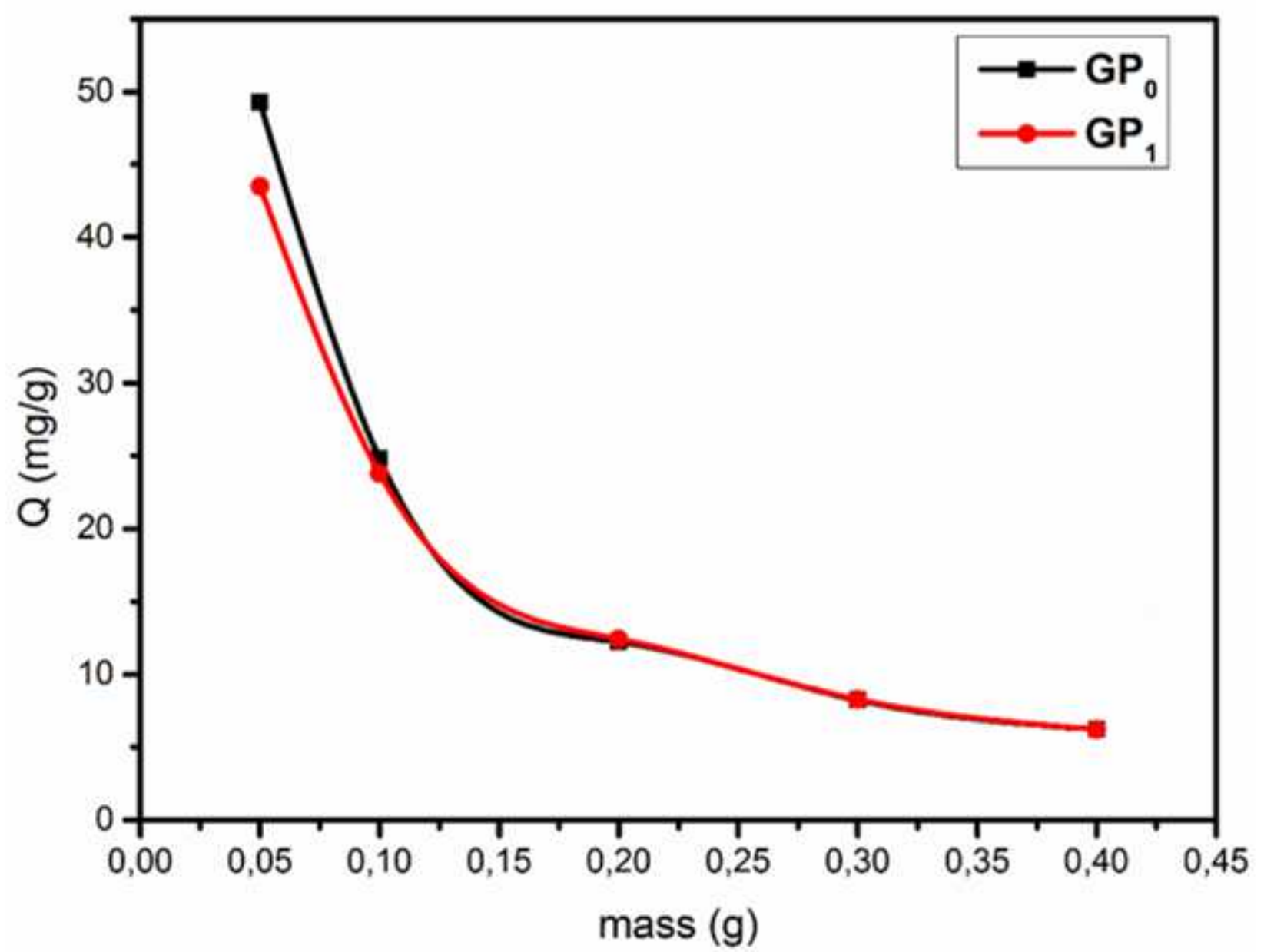

Figure 7

Influence of Adsorbent Dose 


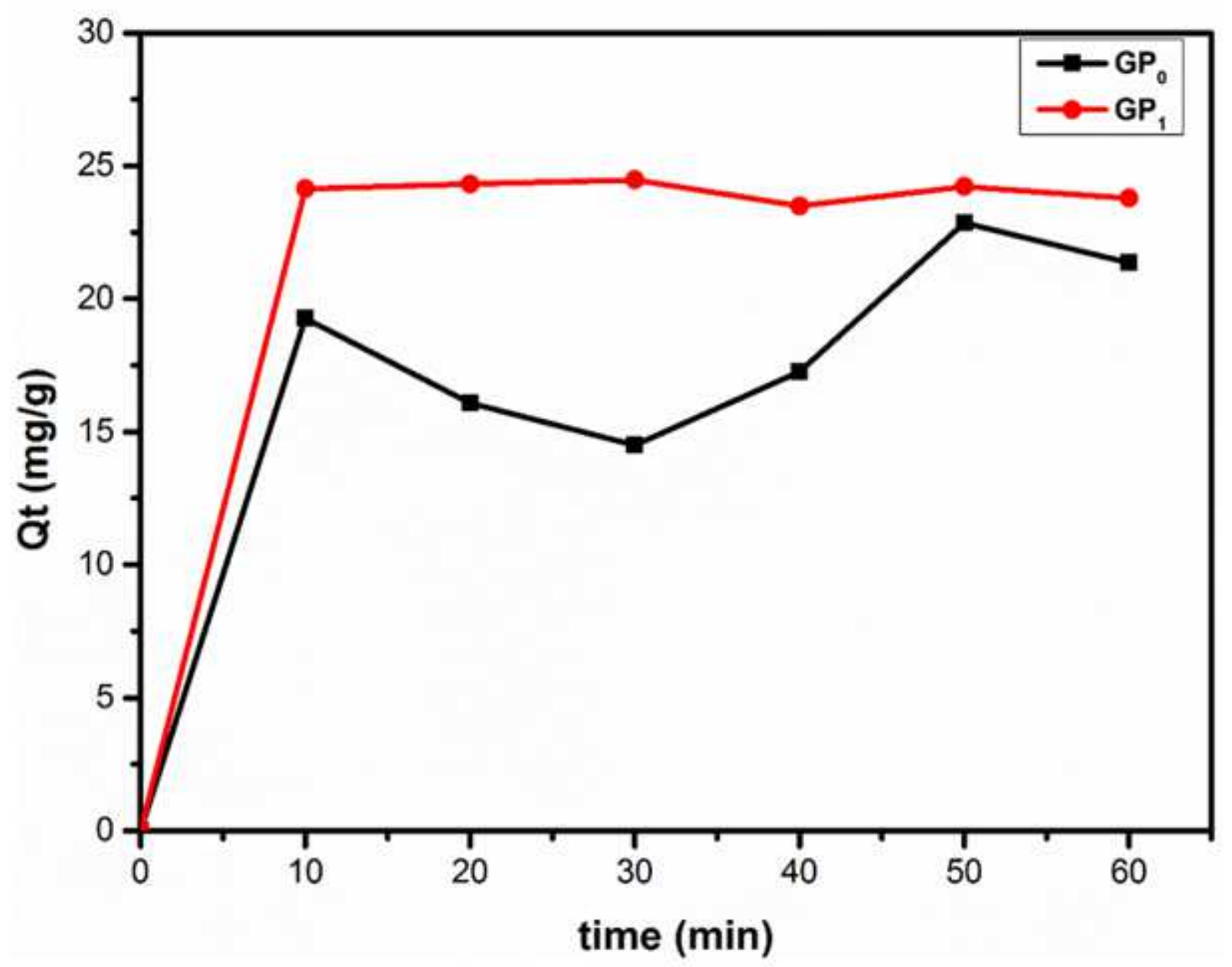

Figure 8

Effect of the MB contact time on the adsorption capacities of the different geopolymers
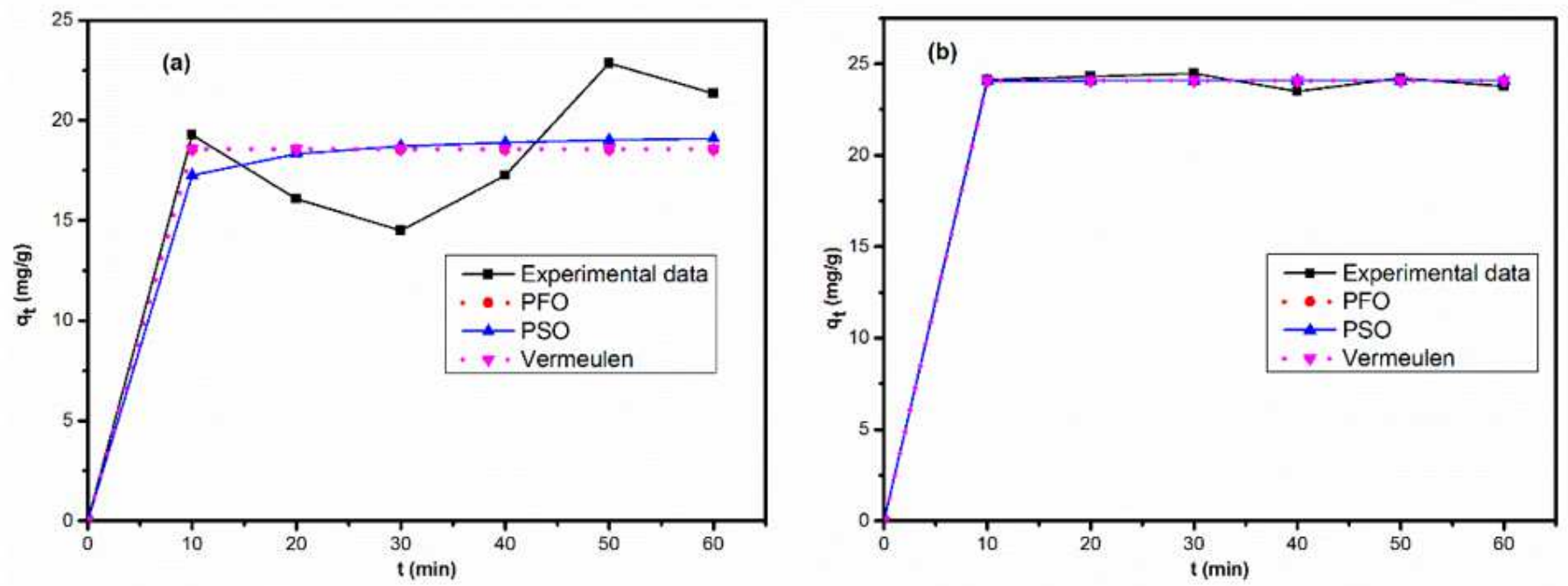

Figure 9 
PFO, PSO and Vermeulen models applied to the experimental kinetic data for the adsorption of MB on different geopolymers ((a) GP0 and (b) GP1)

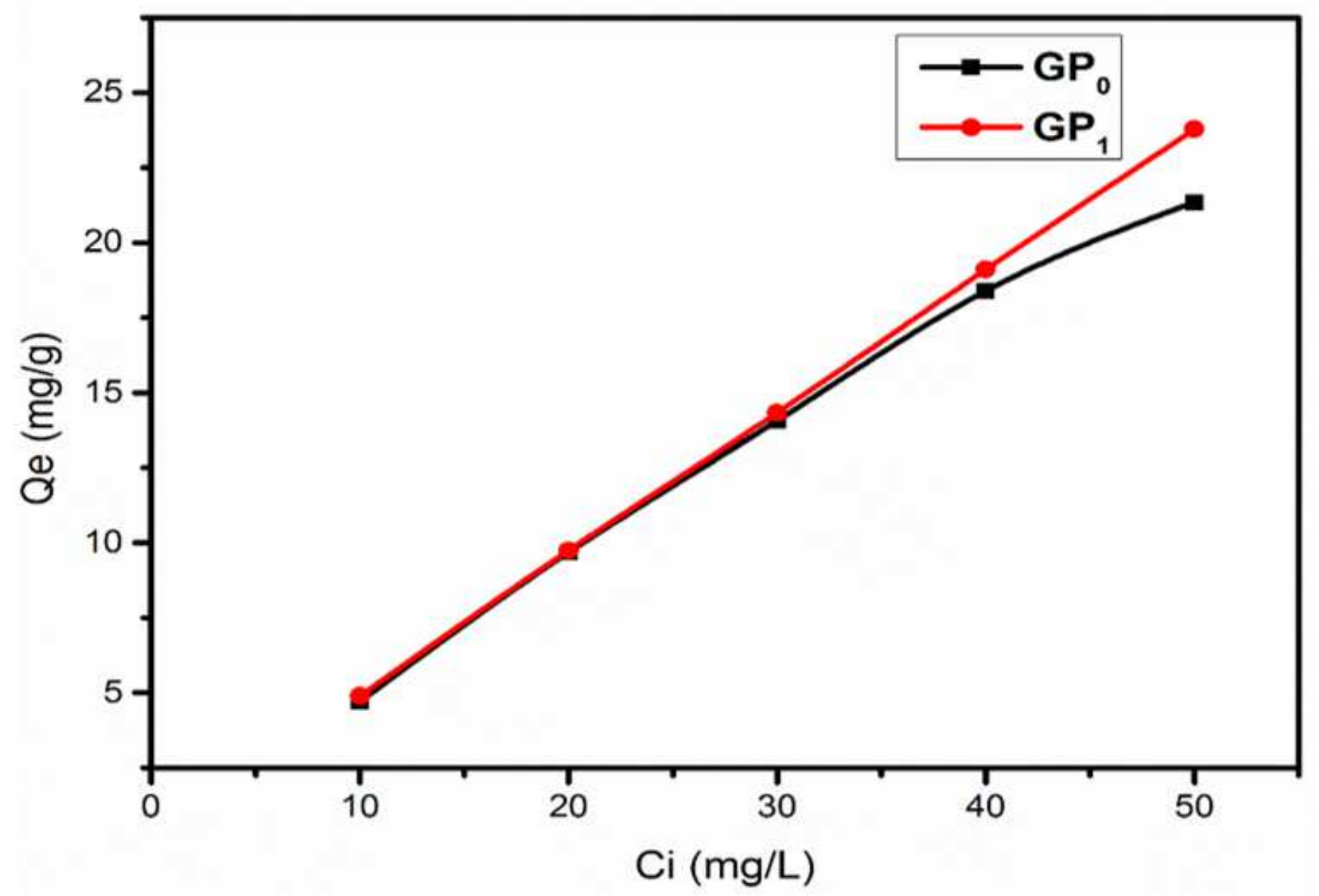

Figure 10

effect of initial concentration 


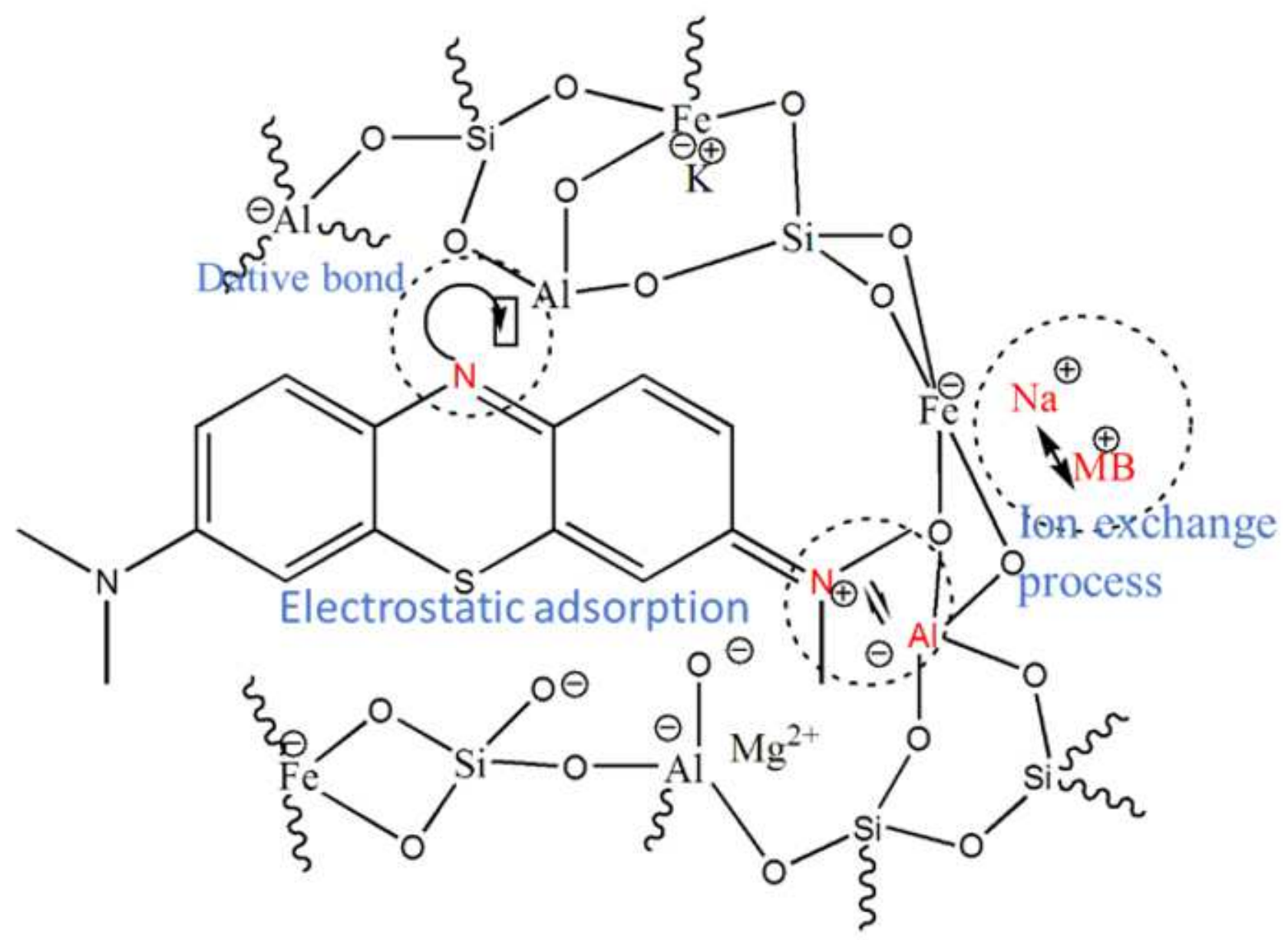

Figure 11

Interaction mechanisms in the GP1-MB system.
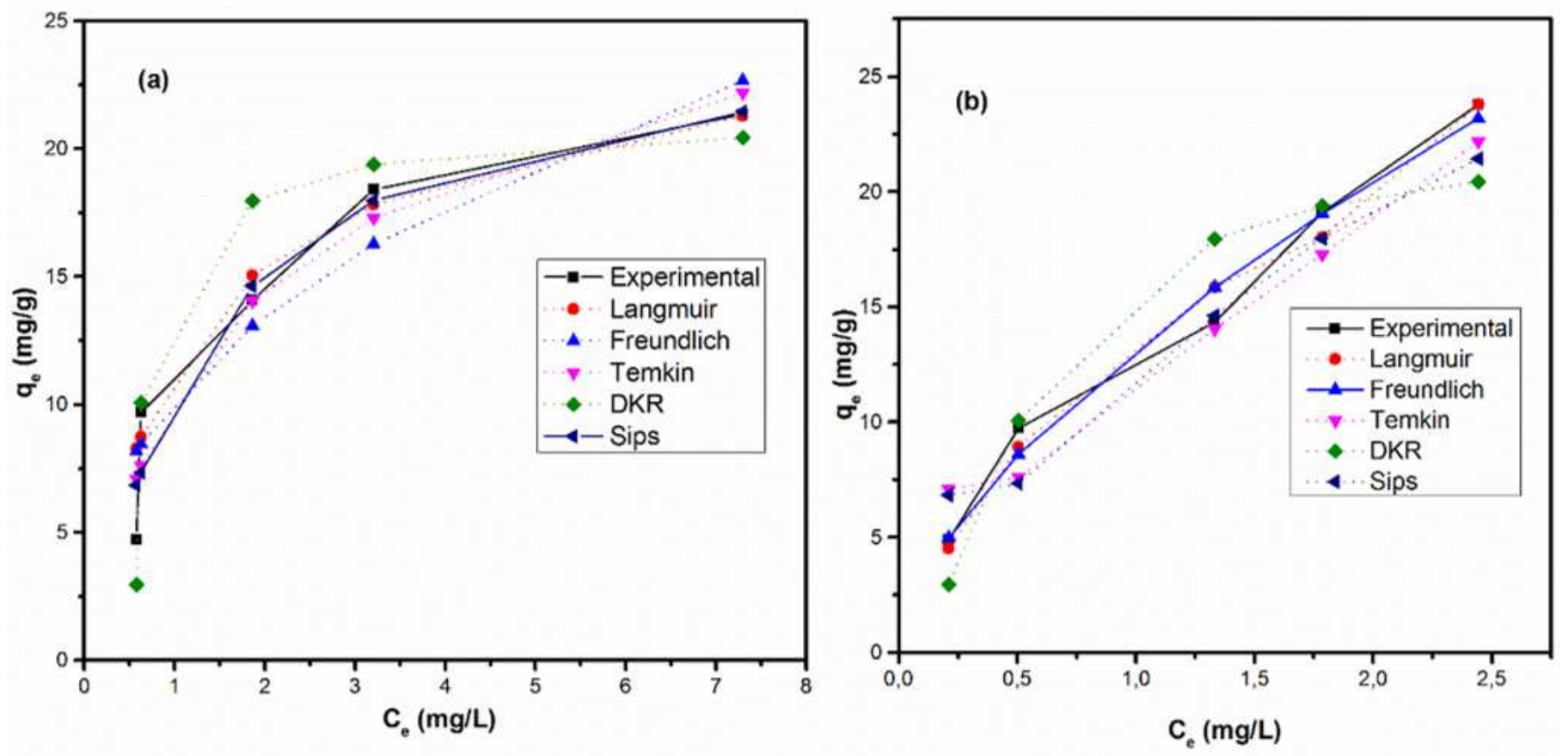
Figure 12

Adsorption isotherm plots for MB onto (a) GP0 and (b) GP1 materials

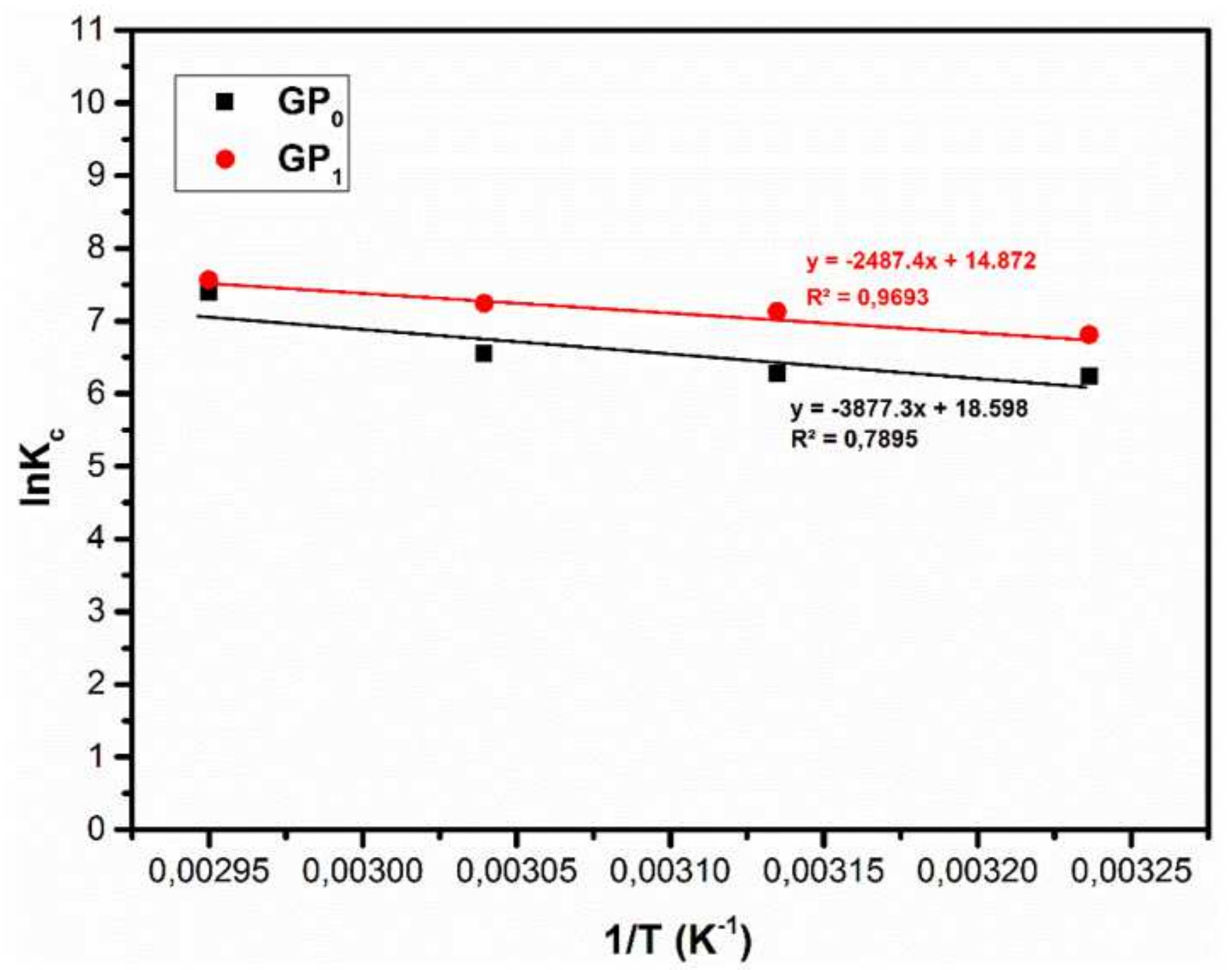

Figure 13

Isotherm plot of van't Hoff.

\section{Supplementary Files}

This is a list of supplementary files associated with this preprint. Click to download.

- Graphicalabstract.docx 